This document is the accepted manuscript version of the following article:

Akkerman, Q. A., Rainò, G., Kovalenko, M. V., \& Manna, L. (2018). Genesis, challenges

and opportunities for colloidal lead halide perovskite nanocrystals. Nature Materials,

17, 394-405. https://doi.org/10.1038/s41563-018-0018-4

\title{
1 Genesis, Challenges and Opportunities for Colloidal Lead Halide 2 Perovskite Nanocrystals
}

3

4

5

6

7

Quinten A. Akkerman ${ }^{1,2}$, Gabriele Rainò, ${ }^{3,4}$ Maksym V. Kovalenko ${ }^{3,4^{*}}$ and Liberato Manna ${ }^{1,5^{*}}$

${ }^{1}$ Nanochemistry Department, Istituto Italiano di Tecnologia, Via Morego 30, 16163 Genova, Italy

${ }^{2}$ Università degli Studi di Genova, Via Dodecaneso, 31, 16146, Genova, Italy

${ }^{3}$ Institute of Inorganic Chemistry, Department of Chemistry and Applied Biosciences, ETH Zürich, Vladimir Prelog Weg 1, CH-8093 Zürich, Switzerland

${ }^{4}$ Laboratory for Thin Films and Photovoltaics, Empa - Swiss Federal Laboratories for Materials Science and Technology, Überlandstrasse 129, CH-860o Dübendorf, Switzerland

${ }^{5}$ Kavli Institute of Nanoscience and Department of Chemical Engineering, Delft University of Technology, PO Box 5, 260oAA, Delft, The Netherlands

*e-mail: mvkovalenko@ethz.ch; liberato.manna@iit.it

Abstract. Lead halide perovskites (LHPs) in the form of nanometer-sized colloidal crystals (nanocrystals, NCs) have attracted the attention of diverse materials scientists due to their unique optical versatility, high photoluminescence quantum yields and facile synthesis. LHP NCs have a "soft" and predominantly ionic lattice, and their optical and electronic properties are highly tolerant to structural defects and surface states. Therefore, they cannot be approached with the same experimental mindset and theoretical framework as conventional semiconductor NCs. In this review, we discuss LHP NCs historical and current research pursuits, challenges in applications, and the related present and future mitigation strategies explored. 
One way of introducing lead halide perovskites nanocrystals (LHP NCs) is to place them in the context of research on colloidal semiconductors $\mathrm{NCs}$, which started several decades ago and that is still flourishing. A historical account on LHP NCs research, beginning from early studies on metal halides, is reported in Box 1. The next section will give a snapshot of the main structural features of LHP NCs and their synthesis approaches. The challenges related to the stability of LHP NCs and possible strategies to address this issue will be discussed in the subsequent sections. Finally, prospects for applications in consumer optoelectronics, as well as in single-photon sources will be provided. For other aspects of colloidal LHP NCs, we refer the reader to several recent reviews. ${ }^{1-3}$

\section{Soft ionic crystal structure and facile synthesis of LHP NCs}

Traditional colloidal semiconductor $\mathrm{NCs}$, which have been actively investigated since the discovery of the hot-injection, high-temperature synthesis of $\mathrm{Cd}$ chalcogenide $\mathrm{NCs},{ }^{4}$ primarily constitute binary compounds with rather simple crystal structure types: tetrahedrally-bonded compounds of zinc-blende (chalcogenides: ZnS, ZnSe, CdS, CdSe, HgTe; pnictides: InP, InAs) or wurtzite (ZnS, ZnSe, CdS, CdSe) structure, or face-centered rock-salt-type compounds ( $\mathrm{PbS}, \mathrm{PbSe}$ ). In this review, those semiconductor NCs which are spheres or cubes smaller than $20 \mathrm{~nm}$ and are therefore quantum-confined in all three dimensions, are also termed quantum dots (QDs). The anions and cations in the crystals of these traditional semiconductor $\mathrm{NCs}$ have crystallographically identical positions/sublattices. LHPs (Fig. 1a) instead crystallize in the cubic $\mathrm{APbX}_{3}$-type perovskite lattice [where A is methylammonium ( $\mathrm{MA}, \mathrm{CH}_{3} \mathrm{NH}_{3}{ }^{+}$), formamidinium $\left(\mathrm{FA}, \mathrm{CH}\left(\mathrm{NH}_{2}\right)_{2}{ }^{+}\right.$) or cesium $\left(\mathrm{Cs}^{+}\right), \mathrm{X}$ is one or more halides $\left(\mathrm{Cl}^{-}, \mathrm{Br}^{-}\right.$or $\left.\left.\mathrm{I}^{-}\right)\right]$or its octahedrally tilted variants, isostructural to traditional oxide perovskites such as $\mathrm{CaTiO}_{3}$. These structures are characterized by the 3-dimensional $\left.{ }_{3} \mathrm{D}\right)$ interconnection of their $\left[\mathrm{PbX}_{6}\right]^{4-}$ octahedra, with the A-site cation residing in the large voids in between. The typically cubic or orthorhombic symmetries of these lattices are apparent in the commonplace observation of the cuboidal shapes of the LHP NCs (Fig. 1b). According to the Goldschmidt tolerance factor, which concerns the close-packing of ions, only MA, FA and $\mathrm{Cs}$ ions can stabilize the ${ }_{3} \mathrm{D} \mathrm{PbX}_{6}$ framework due to their geometric fitness within a twelve-coordinate A-site. Larger or smaller cations favor the formation of polymorphs of a lower dimensionality (oD, $1 \mathrm{D}$ or $2 \mathrm{D})$ ), 
with edge- or face-sharing of the octahedra, and as a consequence, larger and often indirect energy bandgaps. ${ }^{5}$ For a more detailed account of the peculiarities of the crystal chemistry of divalent metal perovskites, we direct the reader to a recent review article. ${ }^{6}$ Here we emphasize that unlike the oxide perovskites, LHPs exhibit much lower melting points (400$500{ }^{\circ} \mathrm{C}$ in $\mathrm{CsPbX}_{3}$ ) due to lower ionic charges and larger interatomic distances, as well as a higher propensity to thermal decomposition (below $300{ }^{\circ} \mathrm{C}$ for MA- andFA-based materials).

The chemical bonding in LHPs is intrinsically much more ionic than in the more rigid, highly covalent lattices of metal chalcogenides and pnictides. This has broad implications for the synthesis, surface functionalization and processing of LHP NCs. Conventional QDs require elevated synthesis temperatures in order to promote crystallization. Existing hotinjection synthesis methods, typically at temperatures of $100-350{ }^{\circ} \mathrm{C}$, are ideal for NCs of moderately ionic compounds such as $\mathrm{Cd}$ and $\mathrm{Pb}$ chalcogenides, and to a large extent also for InP QDs. However, it remains challenging to synthesize high-quality Si and GaAs QDs in the standard solution phase fashion, even at temperatures as high as $400{ }^{\circ} \mathrm{C} .{ }^{7}$ Their synthesis also requires molecular precursors that are highly air-, moisture- or heat-sensitive or difficult to make. In contrast, due to their highly ionic bonding, LHP NCs form within seconds even at room-temperature (RT), from a vast selection of precursors. ${ }^{8-10}$ Initially, the synthesis and processing of $\mathrm{CsPbX}_{3} \mathrm{NCs}$ were primarily approached with the same methods as conventional QDs. For example, ligand-assisted hot-injection synthesis $\left(\mathrm{RT}-200{ }^{\circ} \mathrm{C}\right)$ was used to synthesize the first $\mathrm{CsPbX}{ }_{3} \mathrm{NCs} .{ }^{9}$ An alternative strategy is the ligandassisted reprecipitation method, wherein an ionic solution of the respective ions $\left(\mathrm{A}^{+}, \mathrm{Pb}^{2+}\right.$ and $\left.\mathrm{X}^{-}\right)$in a polar solvent is rapidly destabilized by mixing with a non-solvent inducing a burst of nucleation, as originally proposed for $\mathrm{MAPbBr}_{3} \mathrm{NCs}{ }^{8}$ Both methods are applicable to the whole $\mathrm{APbX}_{3}$ family and the reaction conditions can be adjusted to yield non-cuboidal shapes, such as nanoplatelets, nanosheets and nanowires., ${ }^{21-13}$ Other facile routes to colloidal LHPs include microwave-assisted synthesis, sonication of the precursors in a solvent/ligand mixture and ball-milling. ${ }^{14-16}$ Automated, high-throughput screening, such as using robotics ${ }^{17}$ or microfluidics equipped with on-line optical characterization, ${ }^{18}$ can also enable accelerated progress in the discovery of novel perovskite NCs.

The major practical challenges facing LHP NCs are related to their highly labile structure, as discussed in detail in a dedicated section of this review. Nanoplatelets, nanosheets and 
nanowires are typically fully stable in their crude solution after synthesis, but eventually convert to cuboidal or other irregular shapes, or recrystallize into the bulk material upon isolation and purification, upon concentration or dilution, or under strong UV irradiation. In the case of nanowires, satisfactory durability is found only in wires with a diameter of 10$200 \mathrm{~nm}$. Thus far, the synthesis of stable, few-nm sized QDs or atomically-sized clusters has remained elusive for LHPs. Sub- 5 nm quantum-confined LHP NCs could be produced, but only via non-colloidal approaches, by the ligand-free, templated growth of LHP in ordered mesoporous silica scaffolds. ${ }^{19,20}$

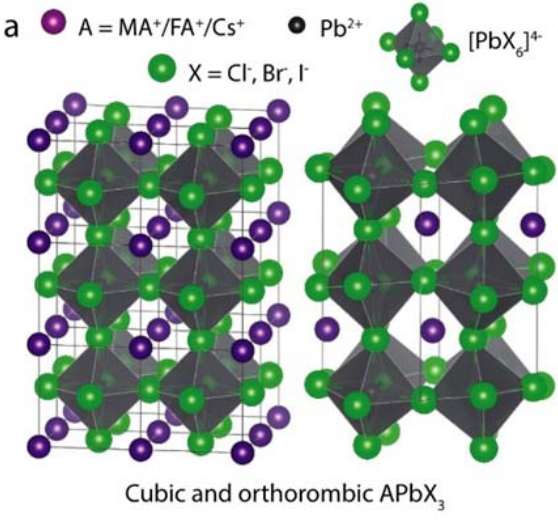

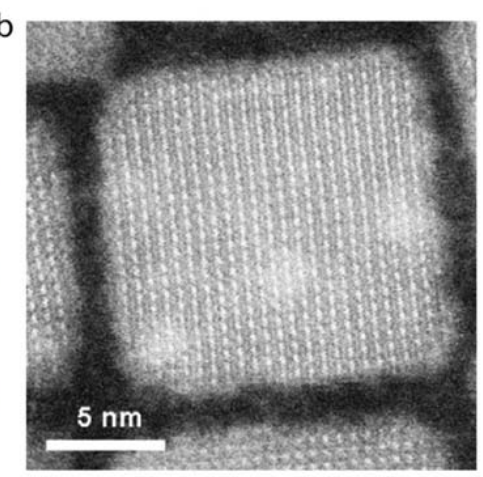

$\mathrm{CsPbBr}_{3}$ nanocrystal

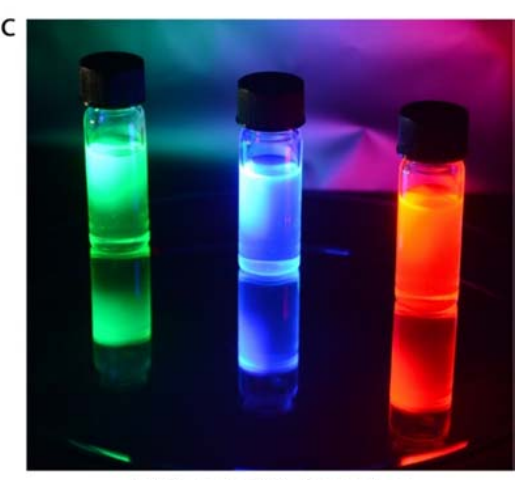

$\mathrm{APbX}_{3}$ collodial dispersions

Figure 1. Colloidal lead halide perovskite nanocrystals. (a) The $\mathrm{APbX}_{3}$ perovskite structure with 3D-corner-sharing octahedra. Two typical structures are shown: cubic $\left(\mathrm{MAPbX}_{3}, \mathrm{FAPbX}_{3}\right.$; two unit cells shown) on the left and orthorhombic $(\mathrm{CsPbX})$ on the right; (b) high-angle annular dark-field scanning transmission electron micrograph (HAADF-STEM) of a single, cube-shaped $\mathrm{CsPbBr}_{3} \mathrm{NC}$, with $15 \mathrm{~nm}$ edge length; (c) photograph of highly luminescent colloidal LHP NCs (from left to right, $\mathrm{CsPbBr}_{3}$ with emission peak at $520 \mathrm{~nm}, \mathrm{CsPb}(\mathrm{Cl} / \mathrm{Br})_{3}$ emitting at $450 \mathrm{~nm}$ and $\mathrm{FAPb}(\mathrm{Br} / \mathrm{I})_{3}$ emitting at $640 n m)$. Figure (c) is courtesy of Dr. Yevhen Shynkarenko.

\section{Defect tolerance}

Conventional wisdom, developed over decades of research on $\mathrm{Si}, \mathrm{CdTe}, \mathrm{GaAs}$ and other conventional semiconductors, holds that PV-grade electronic quality requires ultralow concentrations of impurities and crystalline defects, typically at ppb-levels, that all act as dopants or electronic traps. LHPs are different, as highly efficient LHP PV devices can be easily fabricated based on polycrystalline films synthesized with technical-purity chemicals at low temperatures, deposited in an ambient atmosphere and, often, containing an ultra-high density of point defects such as vacancies (up to 1-2 atomic \%). Likewise, LHP NCs are bright 
emitters without electronic surface passivation. It is clear that the electronic properties of LHPs are highly tolerant to the material's defects and surfaces. ${ }^{21}$ This defect tolerance seems to be a fortunate coincidence of several factors. Firstly, out of a large variety of conceivable point defects, only vacancies (primarily A- and X-site vacancies, Fig. 2a) are characterized by sufficiently low formation energies and are therefore exclusively observed. Interstitial and anti-site defects, which would form deep trap states in the electronic structure, are almost absent ${ }^{22,23}$ since ions in the perovskite lattice are energetically difficult to misplace. Secondly, the shallow character of the vacancy-related states is due to unique specifics of the bonding in LHPs, namely the antibonding character of the valence band maxima (with mixed I 5P and $\mathrm{Pb}$ 6s character; Fig. 2b) and spin-orbit effects in the conduction band (which has a predominant $\mathrm{Pb} 6 \mathrm{p}$ character). $\mathrm{NC}$ surfaces can simply be imagined as a plane of vacancies and should therefore exhibit similarly benign behavior as vacancies. This intuition explains the observation of high PL QYs without surface passivation in LHP NCs. However, it should be also pointed that LHP NCs are not entirely defect-free, as PL QYs are normally reported in the range of $80-95 \%$ in the green-red region and down to $10-20 \%$ at the blue border region (close to $400 \mathrm{~nm}$, i.e., $\mathrm{CsPbCl}_{3}$ ). Yet, these values greatly exceed any other non-passivated QD material in the same range of wavelengths. There exist multiple reports of the beneficial effects of various post-synthetic ligand treatments, such as with thiocyanates, $\mathrm{PbBr}_{2}$ or trioctylphosphine- $\mathrm{PbI}_{2}$, raising the PL QY close to $100 \%,{ }^{24,}{ }^{25}$ presumably due to the improved passivation of under-coordinated $\mathrm{Pb}$ ions. Thirdly, the soft and dynamic nature of the perovskite lattice is such that this material has been defined a "crystalline liquid", to highlight the simultaneous emergence of its crystalline and liquid-like properties. These features seem to protect its carriers from trapping and scattering. ${ }^{26}$ Together with its partial ionic character, the intense structural dynamics of $\mathrm{PbX}$ lattices at RT leads to the coupling of electrons and holes with ionic displacements or, in other words, the formation of polarons (Fig. 2c). These polarons have been proposed to screen the Coulombic potential and reduce trapping and carrier scattering, both mutually and with charged defects and optical phonons. ${ }^{26,27}$ In hybrid perovskites, the A-site molecular rotational motion on the (sub-) ps timescale also allows for the screening of hot carriers, ${ }^{26,}{ }^{27}$ which potentially creates the possibility of harnessing the hot-carrier energy in order to improve the efficiency of solar cells or to observe hot-carrier PL.

The defect tolerance of LHPs, emerging from the $\mathrm{s}$ and $\mathrm{p}$ contributions of the $\mathrm{Pb}$ atoms, is also pronounced in $\mathrm{Pb}$ chalcogenide $\mathrm{NCs}$, which exhibit bright $\mathrm{PL}$ without surface 
modification except when oxidized. The far greater complexity of the defect formation in $\mathrm{Pb}$ chalcogenide NCs has been recently summarized, ${ }^{28}$ pointing out the importance of the dielectric constant, effective masses and defect-defect interactions in these mechanisms. Interestingly, the role of defect-defect interactions might be engineerable by external impurities. Overall, a unified understanding of the exceptional defect-tolerance in LHPs has not been achieved at the current time.

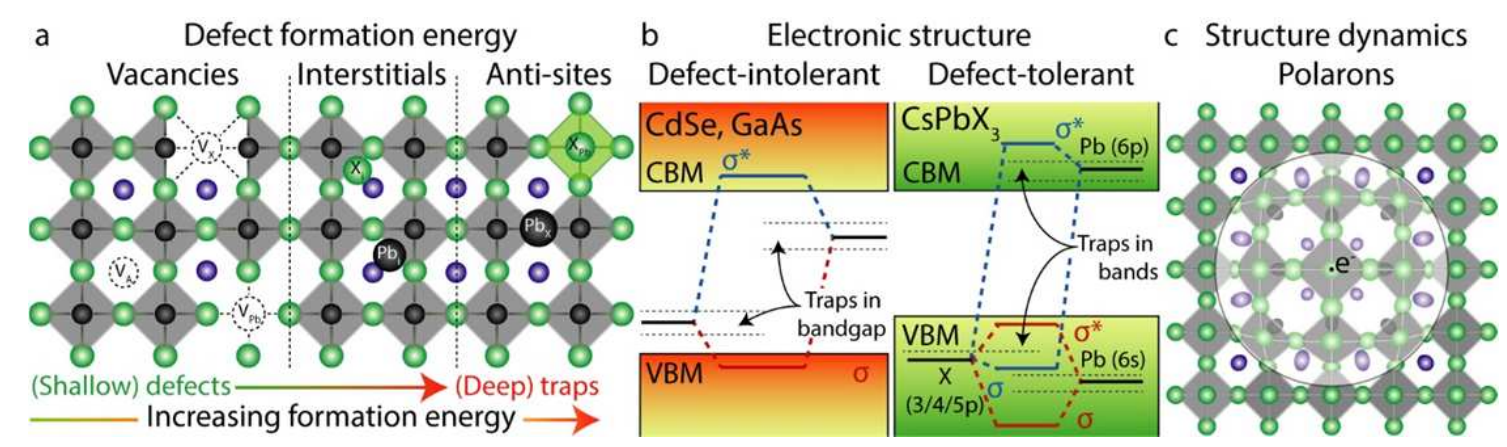

Figure 2. Factors contributing to the defect-tolerant behavior of LHPs. Overall, the defect-tolerance in perovskite NCs emerges from three distinctive features: their crystal structure, favoring the formation of vacancies but no other point defects; their peculiar electronic structure that makes vacancies benign; and their dynamic lattice effects such as formation of polarons, thereby preventing carriers from trapping. (a) Typical point defects in LHPs, including vacancies, interstitial and anti-site atoms, in order of increasing formation energy (or decreasing probability of occurrence), and their depths in the bandgap. (b) Schematic representation of electronic band structure of typical defect-intolerant semiconductors and LHPs. In conventional semiconductors, such as cadmium chalcogenides, the bandgap is formed between bonding $(\sigma)$ and antibonding $\left(\sigma^{*}\right)$ orbitals. Point defects or dangling bonds emerge as weak bonding or non-bonding states within the bandgap. In LHPs, the bandgap is formed between two anti-bonding orbitals. Defects states will thus form only shallow traps or will be enclosed in the conduction or valance band, and will thus not strongly influence the radiative recombination and other optical properties. (c) Schematic representation of local structural deformation of the $\mathrm{Pb}-\mathrm{Br}$ framework that, combined with a charge carrier (electron or hole), forms a polaron.

\section{Structural lability and how to handle it}

Structural and optical stability will remain as the foremost challenge for LHP NCs in the research spotlight. An important paradigm about LHP NCs is that, as easy as it is to make them, it is just as easy to break them. Hence, the retention of their colloidal and structural integrity during isolation, purification and handling has been a problem of paramount importance. The ligand chemistries of conventional QDs have so far primarily relied on 
long-alkyl-chain ligands bound to the NC surface via a single anchoring group, ${ }^{29}$ or on carboxylate or phosphonate (X-type) ligands attached at surface metal adatoms. ${ }^{29}{ }^{30}$ LHP NCs are terminated by oleylammonium bromide and/or oleylammonium carboxylate. ${ }^{30}$ Each of these coordinates to the surface as an ionic pair: ammonium groups displace a surface Asite cation, whereas carboxylates (bromides) act as surface anions. These ligands tend to quickly desorb (Fig. 3a). ${ }^{30}$ The most dramatic consequence of such loose ligand binding is the difficulty met in isolating and purifying colloids using standard methods for QDs, namely by a repetitive precipitation with a non-solvent followed by redispersion in a pure solvent. More static surface coordination might be expected from the ligands containing several anchoring groups, such as zwitterionic molecules (Fig. 3b), containing quaternary ammonium and carboxylate groups (or sulfonate, phosphonate, or other groups). Oligomeric ligands with a larger number of these charged groups and long hydrocarbon chains per molecule can be envisaged as well.

The fairly ionic bonding character and low crystal lattice energy render LHPs somewhat soluble in nearly all polar organic solvents; in practice, this eventually disintegrates LHP NCs upon exposure to such solvents. This problem will remain difficult to mitigate until a strategy for the full encapsulation of individual LHP NCs in an inert shell is identified (for instance, within silica, titania, alumina, salts with extremely low solubility products such as $\mathrm{BaSO}_{4}$ or similar, see Fig. 3c). A classical approach to coating LHP NCs with $\mathrm{SiO}_{2,}$ however, would require adapting a sol-gel process such as the Stöber method. This has not been demonstrated yet, presumably due to the necessity of using alcohols or similar protic polar solvents. As a result of LHP NCs being so fragile, complex morphologies, such as core-shell NCs and other NC heterostructures, have not been demonstrated to this date.

Intrinsic chemical instability remains the major issue concerning MA-based LHPs and, to a far lesser but still significant extent, $\mathrm{FAPbX}_{3}$. MA-based LHP compounds have a low energy of formation and even decompose at RT. This decomposition is reportedly accelerated by heat, light, moisture and oxygen, as well as by the high surface area of the NCs, yielding $\mathrm{PbX}_{2}$ and several volatile products $\left(\mathrm{CH}_{3} \mathrm{NH}_{2}, \mathrm{HI}, \mathrm{I}_{2}\right.$ and other species). Thus, future applications are foreseen to be primarily limited to FA- and Cs-based LHP NCs. Poor thermal stability is another major challenge for nearly all future applications of LHP NCs. Hybrid organic-inorganic LHPs decompose before melting ( $\mathrm{MAPbI}_{3}$ at ca. $150-200{ }^{\circ} \mathrm{C}$; 
$\mathrm{FAPbI}_{3}$ at $\mathrm{ca} \cdot \mathbf{2 9 0}^{2}-300{ }^{\circ} \mathrm{C}$ ), while the melting points of fully inorganic LHPs are slightly higher $\left(450-500{ }^{\circ} \mathrm{C}\right.$ for $\mathrm{CsPbBr}_{3}$ and $\mathrm{CsPbI}_{3}$ ). LHP NCs are all highly prone to sintering. This poses a great challenge for any device architecture relying on the retention of quantumconfined states in a densely packed array of LHP NCs or for devices operating at elevated temperatures, such as lasers or remote phosphors.

Another form of structural lability is observed in red-emitting $\mathrm{CsPbI}_{3}$ (both in the bulk and in NCs). In this case, the $\mathrm{Cs}^{+}$ions are too small to be included in a $3 \mathrm{D}$ perovskite $\mathrm{Pb}$-iodide cage, causing the transition to another polymorph of a lower dimensionality and, hence, a much wider bandgap. ${ }^{31,32}$ It has, on the other hand, also often been reported that a variation in the purification procedure and the exclusion of air during handling and storage do extend the lifetime of metastable $3 \mathrm{D}-\mathrm{CsPbI}_{3}$ phases. ${ }^{33-35}$ Considerable work has been done, both with NCs and thin films, to stabilize $\mathrm{CsPbI}_{3}$ by partially replacing $\mathrm{Cs}^{+}$with larger cations (the foremost example being $\mathrm{FA}^{+}$), and by partially replacing $\mathrm{I}^{-}$with $\mathrm{Br}^{-} \cdot 34,{ }^{6}$ A similar stabilization effect was reported for the replacement of $\mathrm{Pb}^{2+}$ with smaller cations such as $\mathrm{Mn}^{2+}$ and $\mathrm{Bi}^{3+}$, as shown by a retention of bright red PL. ${ }^{37-39}$

Beyond solution-phase chemistry, another underestimated opportunity might deserve further attention, especially in the context of the thermal and environmental stabilization of LHPs. Dynamic structural disorder on fs-ps timescales suggests that it might be very difficult if not impossible to coat LHP NCs with crystalline shells with interfaces that are structurally stable. A promising alternative path to stable LHP emitters is the melt-growth of glass-embedded LHP NCs (Figure 3d), such as in recent reports employing typical phosphate or borosilicate glasses. ${ }^{40-43}$ Thus-obtained crystalline NCs, whose size is tunable by meltquenching and by adjusting the subsequent thermal conditions, are surrounded by an amorphous, chemically stable, water- and oxygen-impermeable glass matrix. Such glassembedded NCs, easily obtainable in powdered form by a grinding step after quenching the melt, can be easily integrated into any down-conversion-based application of LHP emitters be it backlighting in displays or as a remote phosphor in lighting. 


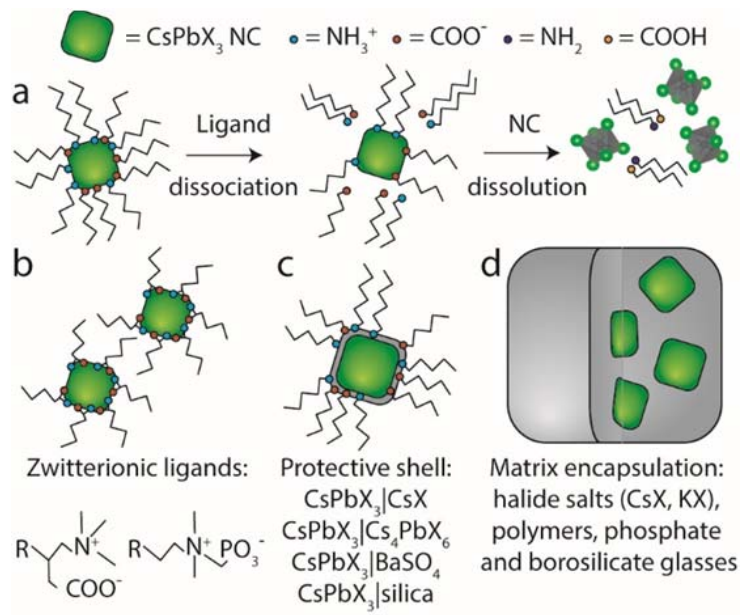

Figure 3. Structural lability of lead halide based perovskite NCs, and stabilization methods. (a) LHP NCs often lose their colloidal stability, or even structural integrity, due to the desorption of weakly bound ligands. Viable strategies for attaining stable surface coverage by ligands include (b) using zwitterionic long-chain molecules; (c) overcoating with dielectric shells or compositionally matched salts; and $(d)$ matrix-encapsulation into polymers with low water and oxygen transmission rates or crystalline and amorphous inorganic matrixes.

\section{From labile LHP NCs to nanocrystal transformers}

The high ionicity and structural instability of LHP NCs can also be exploited for postsynthetic transformations, either with the retention of the original crystal structure, or through reorganization into a new crystal structure. In well-controlled cases, such transformations take place while preserving the overall NC size and shape, or at least the initial size uniformity, as depicted in Figure $4 \cdot{ }^{34,44-47}$ Perhaps the most striking example is that of anion exchange, ${ }^{44}, 45$ whose fast rate can be attributed to the high concentration of halide vacancies and the high mobility of singly charged halide anions. The PL color of LHP NCs can be adjusted by anion-exchange to any wavelength in the visible spectrum, starting from just one progenitor NC sample (Fig. 4a). It has further been established that mixedhalide compositions in NCs are more easily retained than in thin-films, which suffer from photo-induced halide-ion segregation. ${ }^{48}$ In metal chalcogenide NCs, only the cations have been manipulated in a similarly facile way. ${ }^{49}$ In LHPs, the high plasticity of the lattice enables the exchange of both cations and anions. The A-site cations can be partially or fully exchanged $\left(\mathrm{Cs}^{+}\right.$with $\mathrm{FA}^{+}$or $\mathrm{MA}^{+}$, and in reverse), ${ }^{34}$ whereas $\mathrm{Pb}^{2+}$ can be partially exchanged with $\mathrm{Sn}^{2+}, \mathrm{Cd}^{2+}$ and $\mathrm{Zn}^{2+}$ cations (Fig. 4 b,c). ${ }^{47}$ Similarly, doping $\mathrm{CsPbl}_{3} \mathrm{NCs}$ with several at\% 
of $\mathrm{Mn}^{2+}$ yields strongly orange-luminescent $\mathrm{NCs}$ (PL QY $=58 \%$; emission from the dopant)..$^{50} 5^{1}$ Extensive restructuring of LHP NCs is also possible, by either eliminating or adding ions (Fig. $4 \mathrm{~d}$-g). For instance, upon removing $3 / 4$ of the $\mathrm{Pb}$ atoms in the form of $\mathrm{PbX}_{2}$, $\mathrm{CsPbX}_{3} \mathrm{NCs}$ can transform into $\mathrm{Cs}_{4} \mathrm{PbX}_{6} \mathrm{NCs},{ }^{52}$ which are characterized by a structure in which all $\left[\mathrm{PbX}_{6}\right]^{4-}$ octahedra are disconnected from each other (oD-perovskite). Back conversion into $\mathrm{CsPbX}_{3} \mathrm{NCs}$ can be accomplished by re-inserting $\mathrm{PbX}_{2}$ into $\mathrm{Cs}_{4} \mathrm{PbX}_{6} \mathrm{NCs}$ or by extracting $\mathrm{CsX}$ by the action of suitable ligands. ${ }^{46,53,54}$ It is also possible to extract $\mathrm{PbBr}_{2}$ from $\mathrm{CsPbBr}_{3} \mathrm{NCs}$, forming $\mathrm{CsBr}$ NCs or, vice versa, to convert pre-synthesized CsBr NCs into $\mathrm{CsPbX}_{3} \mathrm{NCs}$. These conversions are readily observable owing to a color change due to the large difference in bandgap energies $\left(2.43 \mathrm{eV}\right.$ for $\mathrm{CsPbBr}_{3}, 3.95 \mathrm{eV}$ for $\mathrm{Cs}_{4} \mathrm{PbBr}_{6}$ and 7.3 $\mathrm{eV}$ for $\mathrm{CsBr}$ ). Such chemical transformations, using a presently unexplored variety of A- and B-site metals, will enable the discovery of new functional metal halide NCs, including those that cannot be obtained by direct synthesis.

a Anion exchange

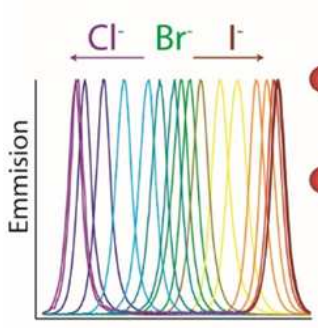

Wavelength

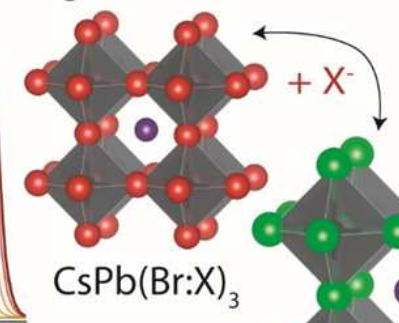

$\mathrm{CsPb}(\mathrm{Br}: \mathrm{X})_{3}$

' $A$ ' cation exchange
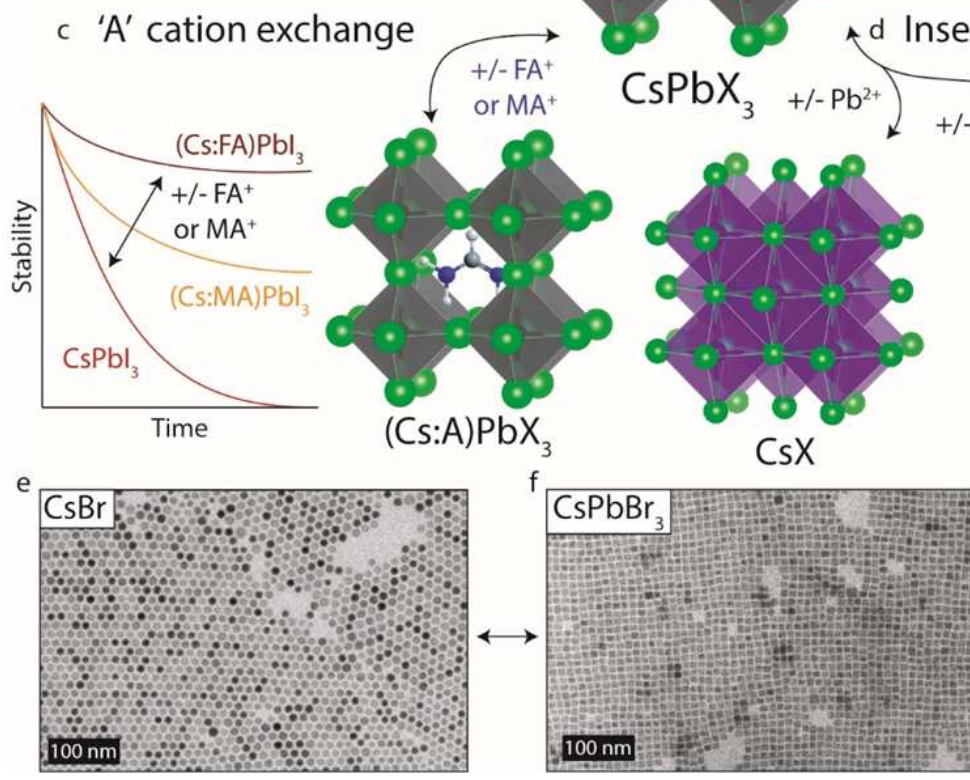

b ' $B$ ' cation exchange
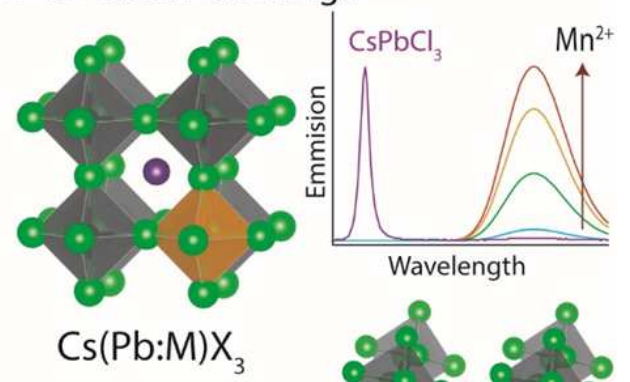

Wavelength
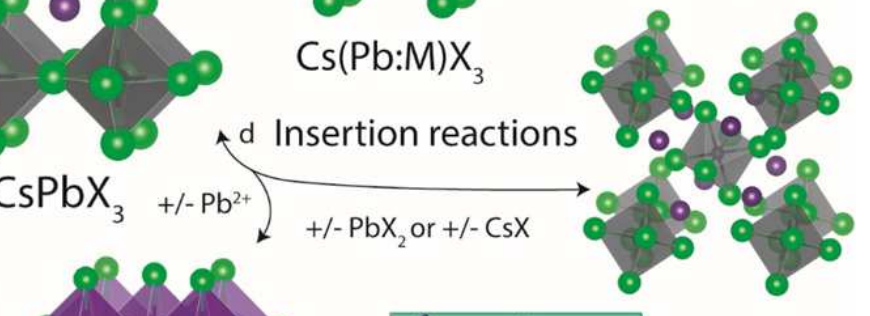

a Insertion reactions
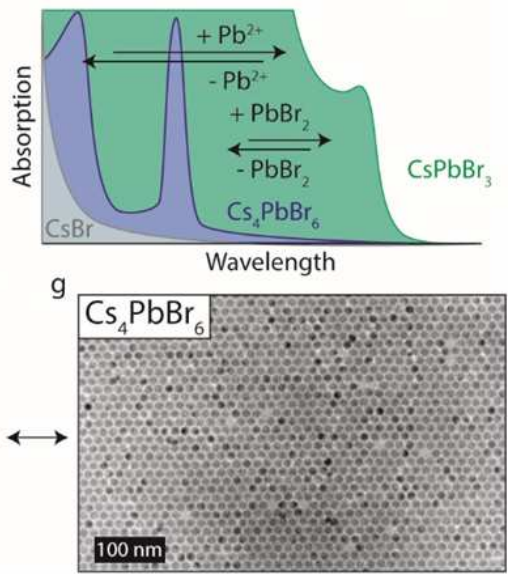

Figure 4. Structural and compositional post-synthetic engineering of lead halide 
as shown in the left inset. (b) "B" cation exchange allows the study of the optical properties of other divalent metals, such as $\mathrm{Mn}^{2+}$ (whose photoluminescence at various concentrations is shown in the right inset) in an LHP environment. (c) " $\mathrm{A}$ " cation exchange allows the tuning of the thermodynamic stability (left inset) of the $3 \mathrm{D}$-LHPs by mixing $\mathrm{Cs}^{+}$with, for instance, $\mathrm{FA}^{+}$, which is key to the stability of iodides. (d) Phase-transformation from $\mathrm{CsPbX}_{3}$ to $\mathrm{Cs}_{4} \mathrm{PbX}_{6}$ and $\mathrm{CsX}$ via reactions with $\mathrm{Pb}^{2+}$ or $\mathrm{PbX}_{2}$. (e-g) TEM images of NCs obtained by deliberate transformations between different $\mathrm{Cs}-\mathrm{Pb}-\mathrm{Br}$ compounds.

LHP NCs vs. conventional QDs. A comparison between the physical and electronic properties of conventional QDs and LHP NCs is shown in Table 1. For decades, the primary challenge facing semiconductor NCs was the suppression of the role of mid-gap surface traps that render practically all as-synthesized semiconductor $\mathrm{NCs}$ that emit in the visible range poorly luminescent. This has been conventionally mitigated by the elaborate synthesis of sophisticated, core-shell CdSe-CdZnS NCs, via decoupling of the excitonic recombination from surface states. These NCs feature high PL QYs of up to 95-100\%, narrow emission lines and excellent long-term stability, and they are currently applied as down-converting materials in several brands of modern liquid-crystal television displays (LCD-TVs) with high color saturation. From the first reports on, unpassivated LHP NCs have exhibited high PL QYs even when the synthesis was performed under ambient conditions and/or without prepurified chemicals. Small FWHM and high PL QYs are also repeatedly reported with more complex, mixed-cation $\mathrm{Cs} / \mathrm{FA}$ and mixed halide $(\mathrm{Cl} / \mathrm{Br}, \mathrm{Br} / \mathrm{I})$ stoichiometries. ${ }^{34}$ Solutionbased compositional engineering has shown to be possible on all three lattice sites within LHPs, such as in $\mathrm{FA}_{0.75} \mathrm{Cs}_{0.25} \mathrm{Sn}_{0.5} \mathrm{~Pb}_{0.5} \mathrm{I}_{3}$ or $(\mathrm{Cs} / \mathrm{Rb} / \mathrm{FA} / \mathrm{MA}) \mathrm{Pb}(\mathrm{Br} / \mathrm{I})_{3}{ }^{55}{ }^{56}$ However, it is difficult to achieve a combination of high optoelectronic quality and atomistic homogeneity in multinary metal chalcogenide NCs $\left(\mathrm{CuInS}_{2}, \mathrm{CuIn}_{\mathrm{x}} \mathrm{Ga}_{(1-\mathrm{x})} \mathrm{Se}_{2} \text { and } \mathrm{Cu}_{2} \mathrm{ZnSnS}_{4}\right)^{57}$ and it remains completely elusive for pnictide NCs. Typically, for the tetrahedrally-bonded compounds, site disorder (interstitial and anti-site atoms) and phase inhomogeneities are enhanced in NCs as compared to the bulk. In contrast, the LHP lattice, wherein ions cannot easily be misplaced due to their specific sizes, coordination numbers and ionic charges, is intrinsically immune to such defects. With regards to multinary LHP NCs such as $(\mathrm{Cs} / \mathrm{FA}) \mathrm{Pb}(\mathrm{Br} / \mathrm{I})_{3}$, a detailed structural analysis is still pending and will be crucial for further taming the presently unstable red and near-IR emitting LHP NCs.

Table 1. Comparison of the chemistry, durability and optical performance of LHP NCs with conventional NCs. Only NCs emissive in the visible spectral range are included. 


\begin{tabular}{|c|c|c|c|}
\hline & $\begin{array}{l}\text { Metal chalcogenide (II-VI) } \\
\text { and pnictide (InP) core- } \\
\text { only nanocrystals }\end{array}$ & $\begin{array}{l}\text { Metal chalcogenide and } \\
\text { pnictide core/shell } \\
\text { nanocrystals }\end{array}$ & $\begin{array}{l}\text { Lead halide perovskite } \\
\text { nanocrystals }\end{array}$ \\
\hline Crystal structure & wurtzite, zinc-blende & wurtzite, zinc-blende & perovskite \\
\hline Composition & CdSe, ZnSe, InP & $\mathrm{CdSe} / \mathrm{CdS}, \mathrm{CdSe} / \mathrm{CdZnS}, \mathrm{InP} / \mathrm{ZnS}$ & $\begin{array}{ll}(\mathrm{Cs}, \mathrm{FA}) \mathrm{PbX}_{3} \quad(\mathrm{X}=\mathrm{Cl}, & \mathrm{Br}, \quad \mathrm{I}), \\
\text { homogeneous, } & \text { multinary } \\
\text { compositions possible } & \end{array}$ \\
\hline Used in & no commercial use & $\begin{array}{l}\text { LCD TV (Samsung, Sony, etc.), } \\
\text { discontinued for Cd-based. }\end{array}$ & under development for LCD TV \\
\hline $\begin{array}{l}\text { Spectral range and } \\
\text { efficiency }\end{array}$ & $\begin{array}{l}\text { entire visible }(400-700 \mathrm{~nm}) \text { for II- } \\
\text { VI and limited for InP }(520-700 \\
\mathrm{nm})\end{array}$ & limited $(510-650 \mathrm{~nm})$ & entire visible (400-70o $\mathrm{nm})$ \\
\hline PL QY & low $(0-10 \%)$ & high (up to $95 \%$ ) & high (up to $99+\%$ ) \\
\hline FWHM & $\begin{array}{l}\text { narrow for II-VI }(<25 \mathrm{~nm} \text {; e.g. }<100 \\
40 \mathrm{~nm} \text { at } 530 \mathrm{~nm} \text { PL peak })\end{array}$ & $\mathrm{meV}$ ), but limited for InP-based (ca. & $\begin{array}{l}\text { narrow over entire visible range } \\
(<100 \mathrm{meV})\end{array}$ \\
\hline Defectiveness & $\begin{array}{l}\text { low in binary compounds; high ir } \\
\text { antisites and interstitials) }\end{array}$ & multinary compositions (vacancies, & intrinsically high (vacancies) \\
\hline Synthesis & $\begin{array}{l}\text { high-purity precursors and } \\
\text { rigorous air-free synthesis; high- } \\
\text { temperature }\end{array}$ & $\begin{array}{l}\text { elaborate, lengthy synthesis; high- } \\
\text { temperatures }\end{array}$ & $\begin{array}{l}\text { facile synthesis; possible under } \\
\text { ambient conditions }\end{array}$ \\
\hline $\begin{array}{l}\text { Post-synthesis } \\
\text { tunability }\end{array}$ & \multicolumn{2}{|l|}{ only cation exchange } & $\begin{array}{l}\text { cation exchange (both } \mathrm{A} \text { and } \mathrm{B} \\
\text { sites) and anion exchange }\end{array}$ \\
\hline Surface ligands & \multicolumn{2}{|c|}{ highly versatile organic and inorganic surface functionalization } & $\begin{array}{l}\text { limited affinity to the surfaces } \\
\text { new ligand chemistries are } \\
\text { urgently needed }\end{array}$ \\
\hline $\begin{array}{l}\text { Heteronanostructu } \\
\text { res }\end{array}$ & \multicolumn{2}{|c|}{ yes (complex core shells/dumbbells/Janus etc.) } & none to date \\
\hline Thermal stability & stable & stable & $\begin{array}{l}\text { limited to below } 100{ }^{\circ} \mathrm{C} \text { due to low } \\
\text { melting points }\end{array}$ \\
\hline $\begin{array}{l}\text { Oxidative and } \\
\text { photostability }\end{array}$ & low to moderate & high & high \\
\hline $\begin{array}{l}\text { Solvent } \\
\text { compatibility }\end{array}$ & \multicolumn{2}{|c|}{ compatible with all solvents, including water } & $\begin{array}{l}\text { finite solubility in water and many } \\
\text { polar solvents, insoluble in all } \\
\text { others }\end{array}$ \\
\hline RoHS compliance & \multicolumn{2}{|c|}{ limited for CdSe-based (100 ppm limit for Cd), unlimited for InP-based } & $\begin{array}{l}\text { limited but higher than for } \mathrm{CdSe} \text { - } \\
\text { based (10oo ppm limit for } \mathrm{Pb} \text { ) }\end{array}$ \\
\hline \multicolumn{4}{|c|}{ Single-dot PL } \\
\hline $\begin{array}{l}\text { Single-photon } \\
\text { emission }\end{array}$ & yes & yes & yes \\
\hline Multi-exciton & low yield & high yield & high yield \\
\hline
\end{tabular}




\begin{tabular}{|l|l|l|l|}
\hline emisison & & & \\
\hline Blinking & yes & reduced & reduced \\
\hline Photobleaching & fast & moderate & moderate \\
\hline Emission rate & $\sim 10 \mathrm{~ns}(\mathrm{RT})$, & $10-100 \mathrm{~ns}(\mathrm{RT})$, & $1-50 \mathrm{~ns}$, longer for iodides (RT), \\
& sub- $\mu \mathrm{s}(5 \mathrm{~K})$ & sub-ns $(5 \mathrm{~K})$ & \\
\hline
\end{tabular}

\section{Consumer optoelectronic devices with LHP NCs}

The wide color gamut of the PL of LHP NCs meets the existing color standards for display applications (Figure 5a). The small FWHM of this PL of $\leq 100 \mathrm{meV}$ corresponds to just $18-20$ $\mathrm{nm}$ in the green region around $\mathbf{5}^{20-530} \mathrm{~nm}\left(\mathrm{CsPBr}_{3}, \mathrm{FAPbBr}_{3} \mathrm{NCs}\right)$, making such emitters valid contenders with traditional green phosphors. A promising near-future application for LHP NCs is therefore in LCD backlighting, for which color-pure green and red emitters with PL peaks centered at $530 \mathrm{~nm}$ and $630 \mathrm{~nm}$ are desired. Closely related prospective applications include remote phosphors for lighting and color-controlling and colorenhancing films in portable gadgets. The InP-based NCs currently used in Samsung SUHD TV displays have broader PL bands (FWHM $\approx 40 \mathrm{~nm}$ at $530 \mathrm{~nm}$ ), which are difficult to improve upon due to inherent compositional and morphological inhomogeneities in the few-nm-sized InP-based emissive cores. Towards display applications, the incorporation of LHP NCs into optically transparent polymers or into an inorganic matrix is an obvious strategy for thermal and environmental stabilization. Encouraging results on the long-term stability of such emitters were indeed obtained by incorporating LHP NCs in waternonpermeable polymers and into salt matrixes (potassium halides or $\mathrm{Cs}_{4} \mathrm{PbX}_{6}$ ). ${ }^{58-6 o}$

The fact that electronic surface passivation with wide-gap shell materials is not required for LHP NCs might be a decisive advantage for facile charge carrier injection in light-emitting diodes (LEDs). Thus far, LEDs based on $\mathrm{CsPbBr}_{3} \mathrm{NCs}$ are the most studied, with typical external quantum efficiencies (EQEs) of $6.3 \%{ }^{61}$ and $8.7 \%{ }^{62}$. The former study reported a peak luminance of over $15^{\prime}$ ooo $\mathrm{cd} / \mathrm{m}^{2}$, while the latter reported a more modest value of $1^{\prime} 66 \mathrm{ocd} / \mathrm{m}^{2}$. Both studies highlight the importance of purifying LHP NCs from excess ligands. Red $\mathrm{CsPbI}_{3}$ NC LEDs showed an EQE of 7.3\% and a peak luminance of $435 \mathrm{~cd} / \mathrm{m}^{2}$ at $688 \mathrm{~nm} .{ }^{63}$ It remains difficult to construct efficient blue LEDs with perovskite NCs, where the best example is that of $\mathrm{MAPbBr}_{1.5} \mathrm{Cl}_{1.5} \mathrm{NCs},{ }^{64}$ which exhibit an EQE of $1.18 \%$ and a peak luminance of $2473 \mathrm{~cd} / \mathrm{m}^{2}$ at 
$445 \mathrm{~nm}$. For the blue-most $\mathrm{CsPbCl}_{3} \mathrm{NCs}$, the highest achieved EQE to date is only $0.61 \%$ and the corresponding luminance was $11 \mathrm{~cd} / \mathrm{m}^{2}$ (at $404 \mathrm{~nm}$ ). ${ }^{63}$

LHP NCs also show great promise as versatile solution-based precursors for the lowtemperature fabrication of absorber layers for PV (Figurer 5 b).${ }^{65}$ Solar cells with efficiencies up to $10.8 \%$ were demonstrated using $\mathrm{CsPbI}_{3} \mathrm{NC}$ thin-films deposited by multiple rounds of sequential spin-coating and ligand-removal steps. ${ }^{33}$ We expect further progress in this direction, utilizing more complex compositions of LHP NCs. This is motivated by recent trends in thin-film LHP PV where power conversion efficiencies exceeding $20 \%$ have been reported, by employing mixed-cation and mixed-anion compositions such as $(\mathrm{Cs} / \mathrm{Rb} / \mathrm{FA} / \mathrm{MA}) \mathrm{Pb}(\mathrm{Br} / \mathrm{I}) 3 .{ }^{56} \mathrm{NC}$-based synthesis routes to such complex thin-films might have certain inherent advantages. For example, although the deposition of such films requires the solubilisation of all of the precursor salts in polar solvents, coating, annealing and recrystallization of the LHPs in a single step, the use of LHP NCs separates the mixing of ions, film-formation and crystallization into three different steps. The nonpolar solvents used for depositing NCs might also be advantageous, for example, in maintaining solvent orthogonality in the deposition from solution of consecutive layers of the device. LHP NCs are also unique in their ability to form bulk heterojunctions with other solution-processable materials such conductive polymers, fullerenes or other QDs.

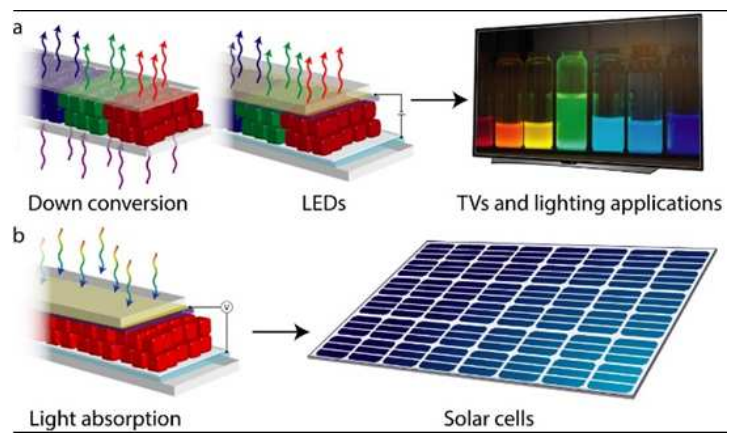

Figure 5. Optoelectronic applications of LHP NCs. Owing to high PL QYs, narrow FWHM and tunability over the entire visible spectral range, LHP NCs can find applications in PL down-conversion (a, LCD displays and lighting), in electroluminescent devices (b, LEDs) and in solar cells (c).

\section{Toxicity of lead and exploration of lead-free LHP NCs}


The presence of lead in LHPs raises obvious concerns about the toxicity of these materials upon introduction into consumer electronics. One should note here that the industrialized world has been exposed to massive amounts of lead over the decades. A now infamous, volatile compound, tetraethyl lead, has been used since the 1920 s an additive to fuels, and although its phasing out from automotive applications began in the 1970s, it is still far from completion. In its non-volatile, metallic form, or as stable and insoluble solid compounds, $\mathrm{Pb}$ remains widely used in, for example, lead-acid batteries, solder in silicon solar cells, piezoelectrics and even as a white pigment $\left(\mathrm{PbO}_{2}\right)$.

The European "Restriction of Hazardous Substances" (RoHS) directive limits the use of heavy-metal-based substances in electrical and electronic equipment. The current limit for lead is 1000 ppm by weight in any continuous solid component of the device, which is not as stringent as the current limit for cadmium (100 ppm by weight). Current Cd-based QD TV displays require only about $1.5 \mathrm{mg}$ of $\mathrm{Cd}$ (for a 55 inch display). ${ }^{66}$ For LHPs, one could assume that roughly the same quantity of $\mathrm{Pb}$ would be needed based on nearly identical extinction coefficients in blue (450-470nm; GaN emission for excitation) and similarly high PL efficiencies at the same PL wavelengths ( 530 and $630 \mathrm{~nm}$ ). This corresponds to sub-10oo ppm concentrations of $\mathrm{Pb}$ within the 50-100 $\mu \mathrm{m}$ thick polymer film, hence not requiring an RoHS exemption. With regard to consumer electronics, the recycling policies for $\mathrm{Pb}$ are well detailed and are highly efficient.

Efforts are underway to find environmentally benign and, at the same time, chemically robust alternatives to lead-based chemistries for optoelectronic applications. As discussed above, defect-tolerant semiconductors are those in which both the s and p electrons of a metal hybridize to form the valence and conduction bands. In accordance with this principle, $\mathrm{Sn}^{2+}$ and $\mathrm{Ge}^{2+}$ analogues of LHPs do exhibit bright emissions but, unfortunately, are highly unstable. Even trace oxygen quantities cause degenerative p-type doping in tin and germanium perovskites through oxidation. Furthermore, Sn-based analogues of LHPs are, from a toxicity point of view, not ideal alternatives. ${ }^{67}$ High stability and bright emission have been reported for oD-perovskite-like structures $\left(\mathrm{C}_{4} \mathrm{~N}_{2} \mathrm{H}_{14} \mathrm{Br}\right){ }_{4} \mathrm{SnX} \mathrm{X}_{6}(\mathrm{X}=\mathrm{Br}, \mathrm{I}){ }^{68}$ but with a very large FWHM of above $100 \mathrm{~nm}$ at RT.

The solar cell community has contributed great effort in the search for lead-free, LHP-like semiconductors. ${ }^{69}$ In particular, the replacement of $\mathrm{Pb}^{2+}$ with oxidatively stable $\mathrm{Bi}^{3+}$ is an 
attractive option. However, such ternary halides are structurally very different from LHPs since they typically crystallize into $\mathrm{oD}$ or $2 \mathrm{D}$ networks of $\mathrm{M}-\mathrm{X}$ polyhedra, usually with indirect band gaps, such as in $\mathrm{Cs}_{3} \mathrm{M}_{2} \mathrm{X}_{9}(\mathrm{M}=\mathrm{Sb}, \mathrm{Bi}, \mathrm{In}){ }^{70}$ So far, these phases have not exhibited efficient PL at RT. To retain the 3 D-interconnection of octahedra, double perovskite compositions of $\mathrm{A}_{2} \mathrm{M}^{1+} \mathrm{M}^{3+} \mathrm{X}_{6}$ have been investigated, such as $\mathrm{Cs}_{2} \mathrm{AgBiCl}_{6}$ and $\mathrm{Cs}_{2} \mathrm{AgInCl}_{6}{ }^{71,72}$ Such compounds have not yet shown photophysical characteristics on par with LHPs, and they exhibit indirect band gaps, making them unsuitable as emitters.

Overall, despite the growing skepticism of the PV community about the near-term probability of finding a substitute for LHPs amongst its close structural and compositional analogues, the chances of developing bright, LHP-like nanoscale emitters are, in our opinion, far greater. The reasons for this optimism are as follows. First, while PV materials must have bandgaps beyond $700 \mathrm{~nm}$, LHP NCs as bright emitters are primarily needed to function with bandgaps of 450-700 $\mathrm{nm}$. Hence, many materials discarded by the PV research community might be perfectly suited for constructing NC emitters. Second, the spatial confinement of carriers in NCs usually drastically enhances the PL QY. To this end, and in retrospect, the bright green PL from $\mathrm{CsPbBr}_{3}$ could have been discovered much earlier; this compound has been known for over 100 years, and all that was needed to be done was intense mechanical grinding of the bulk material. However, this idea would have been hard to conceive of since bulk $\mathrm{CsPBr}_{3}$ is essentially non-luminescent. In conclusion, it seems to make quite some sense to revisit numerous compounds that were discarded as PV materials and to systematically synthesize them in nanoscale form in order to observe whether or not they become luminescent. 

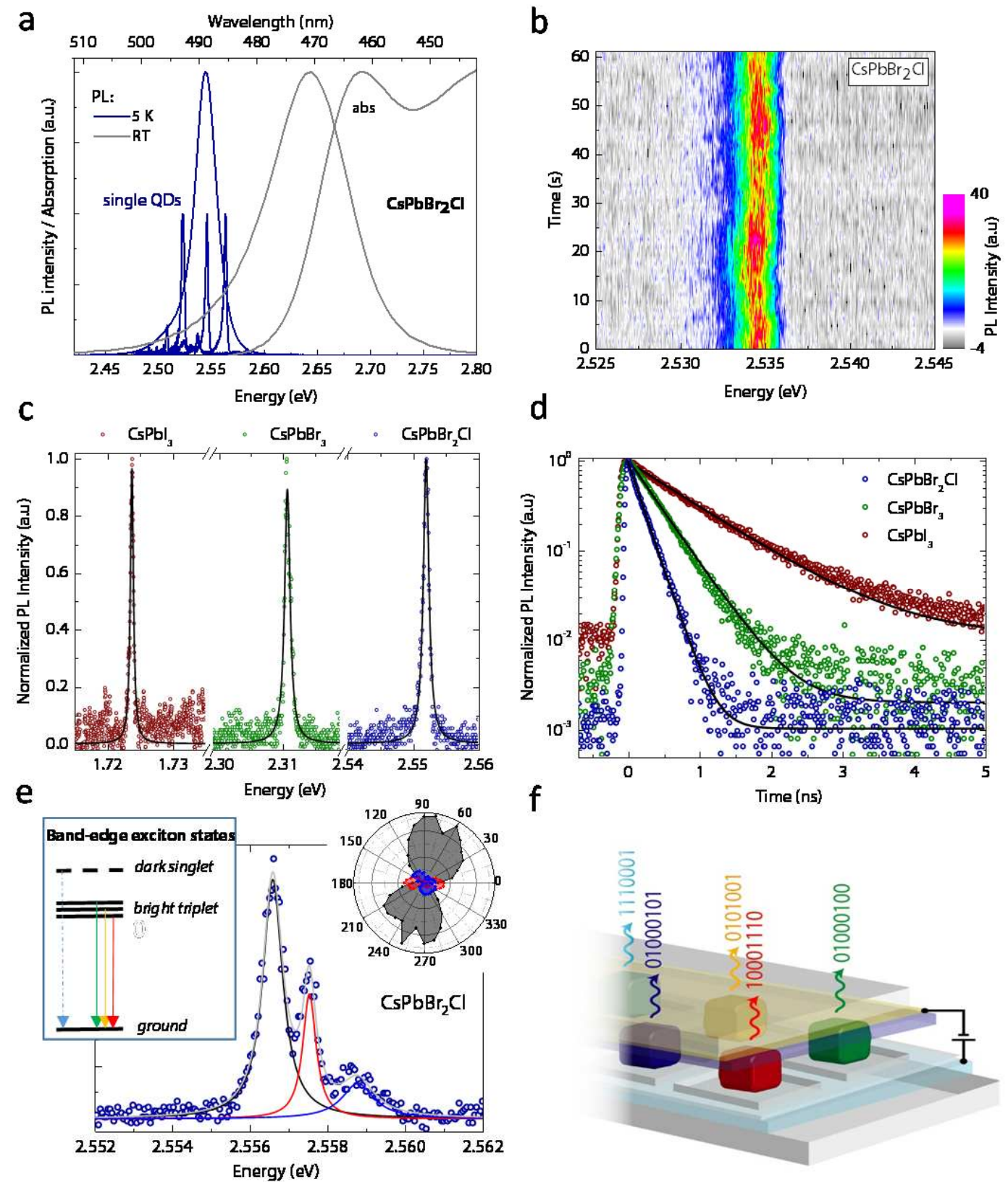

Figure 6. LHP NCs as single-photon sources. (a) Typical ensemble absorption and PL spectra from $\mathrm{CsPbBr}_{2} \mathrm{Cl} \mathrm{NCs}$ recorded at RT, an ensemble PL spectrum recorded at $\mathrm{T}=5 \mathrm{~K}$ and three representative single-dot spectra. (b) Time series of PL from a single $\mathrm{CsPbr}_{2} \mathrm{Cl}$ $\mathrm{NC}$ at $6 \mathrm{~K}$, showing stable emission without blinking and with minimal spectral diffusion. (c) Representative single-dot spectra from $\mathrm{CsPbX}_{3}$ NCs of various compositions. (d) Timeresolved PL traces for NCs of various compositions. (e) Polarization dependent single $\mathrm{CsPbBr}_{2} \mathrm{Cl} \mathrm{NC} \mathrm{PL} \mathrm{spectrum.} \mathrm{The} \mathrm{inset} \mathrm{(top-right)} \mathrm{shows} \mathrm{the} \mathrm{polarization} \mathrm{of} \mathrm{each} \mathrm{of} \mathrm{the}$ spectral features. In this case, three linearly polarized PL peaks are observed. Schematics (top-left) of the band-edge excitonic states in $\mathrm{CsPbX}_{3} \mathrm{NCs}$ comprising a three-fold split bright triplet state and a dark singlet state. (f) Future LEDs featuring individually addressable single NC emitters. Figures (a \& b) are adapted with permission from Ref. ${ }^{73}$ 
Figure (c), courtesy of IBM Research - Zurich (M. A. Becker, T. Stöferle, R. F. Mahrt). Figures (d \& e) are adapted with modifications from Ref. ${ }^{74}$

\section{LHP NCs as single-photon sources}

In addition to conventional optoelectronic devices, colloidal semiconductor NCs can be employed as non-classical light sources (single photon emitters) ${ }^{75}$ that might play a pivotal role in future quantum technologies (such as quantum cryptography, quantum sensing and quantum communication). ${ }^{76}$ At this time, most such studies have concerned CdSe-based NCs. The common challenges of such applications, including emission intermittency (blinking), photo-instability and spectral diffusion, originate from factors that are inherent to the QD material (for instance, surface traps, enhanced Auger processes, facile photoionization, photo-oxidation and other environmental effects). ${ }^{75}$ Specially designed core-shell heterostructures have been shown to reduce blinking, yet at a compromise with respect to enhanced multiphoton emission. ${ }^{75}$

Due to reduced charge trapping on surface states, LHP NCs have become attractive as alternative single-photon emitters. Single particle spectroscopy at low temperatures has revealed that all $\mathrm{CsPbX}_{3} \mathrm{NCs}(\mathrm{X}=\mathrm{Br} / \mathrm{Cl}, \mathrm{Br}$, I; cubes with the edge length of 8-14 $\mathrm{nm}$ in a polymer matrix) investigated thus far are capable of stable, fast and spectrally narrow singlephoton emission (see Fig. 6). ${ }^{73}$ The ensemble PL band of $\mathrm{CsPbBr}_{2} \mathrm{Cl} \mathrm{NCs} \mathrm{(Fig.} \mathrm{6a)} \mathrm{shifts} \mathrm{to}$ lower energies upon cooling to $5 \mathrm{~K}$ (from 2.64 to $2.54 \mathrm{eV}$ ), concomitant with spectral narrowing (from $84 \mathrm{meV}$ to $24 \mathrm{meV}$ ) due to reduced exciton-phonon coupling. This positive bandgap temperature coefficient, is directly opposite to that of conventional semiconductors (II-VI, III-V, and other systems), is characteristic also of other Pb-based semiconductors and originates from the strong $\mathrm{Pb}$ 6s contribution to the valence band (lifting the antibonding states). Individual $\mathrm{CsPbBr}_{2} \mathrm{Cl} \mathrm{NCs}$ exhibit much narrower PL linewidths of ca. $1 \mathrm{meV}$. In these cases, blinking-free PL with strongly reduced spectral diffusion (Fig. 6b) can last up to several hours. NCs of other compositions, such as $\mathrm{CsPbBr}_{3}$ and $\mathrm{CsPb}_{3}$, exhibit equally narrow PL bands (as exemplified in Fig. 6c) with minimal to nonexistent blinking, as reported by several groups. ${ }^{77-79}$

The most remarkable property of this emission, as reported recently ${ }^{74}$ is its high rate: radiative lifetimes as short as just a few hundreds of a picosecond, with pronounced 
composition dependence, have been measured at cryogenic temperatures (Figure 6d). This behavior is remarkably different than that of CdSe-based NCs, which emit at up to a factor of 1000 slower (on the scale of microseconds) at cryogenic temperatures. The origin of the vastly different PL properties of $\mathrm{CsPbX}_{3} \mathrm{NCs}$ was explained by analyzing excitonic energy level ordering at the band-edge using DFT and k·p effective-mass calculations (Figure 6e) ${ }^{74}$. It is notable that this work accounts for the orthorhombicity of the crystal structure, spinorbit coupling and the existence of the Rashba effect. ${ }^{78}$ In CdSe, as in nearly all molecular and semiconductor emitters, the lowest exciton state is optically "dark", causing slow emission at low temperatures. ${ }^{80}$ On the contrary, the triplet state in $\mathrm{CsPbX}_{3} \mathrm{NCs}$ is bright with high oscillator strength. The latter strongly accelerates the radiative recombination decay, rendering $\mathrm{CsPbX}_{3} \mathrm{NCs}$ among the fastest single-photon emitters reported to date. ${ }^{81}$ In addition, this triplet is three-fold orthogonally split, which agrees well with the experimental observation of three, linearly polarized, mutually orthogonal emission bands (Figure 6 e). Due to the small energy difference of just a few meV between the singlet and triplet states, these states are essentially mixed at RT. The low-temperature excitonic fine structure of $\mathrm{CsPbr}_{3} \mathrm{NCs}$ was reported also elsewhere, ${ }^{77}$ and it was suggested that the co-existence of several NC polymorphs, namely tetragonal and orthorhombic types, might explain that comparable numbers of NCs exhibit either 2 or 3 emission lines. Several groups have carried out low-temperature, single-dot spectroscopy in the presence of a magnetic field. ${ }^{77},{ }^{78}$ The nonlinear energy splitting between the polarized transitions versus magnetic field strength in these systems was observed recently. ${ }^{78}$ At low magnetic field, the Rashba effect dominates the energetic splitting whereas the Zeeman effect becomes dominant at fields above $4 \mathrm{~T}$. In that work the origin of the Rashba effect was attributed to a dynamic loss of the inversion symmetry in the orthorhombic $\mathrm{CsPbBr}$, due to, for instance, $\mathrm{Cs}^{+}$motion.

Several other important aspects concern the charged exciton (trion) dynamics in LHP NCs. ${ }^{77}$ At relatively high excitation density, in addition to the multi-lined excitonic fine structure emission, a red-shifted single peak emerges, which has been assigned to trion recombination. Typical trion binding energies range from a few to up to $25 \mathrm{meV}$. Interestingly, the integrated PL intensities of the exciton and trion scale linearly with excitation power density, meaning that the quantum yield of this charged complex is not strongly affected by Auger recombination at low temperatures. This fact is in agreement with minimal single-dot blinking. ${ }^{73}$ 
Obtaining well-behaved single-photon emission is by far more difficult in any systems at RT as compared to cryogenic temperatures. In order for NCs to act as an effective two-level system emitting single photons, efficient mechanisms to suppress multi-photon emission (such as the Auger process) are necessary. A simple spectral filtering would not be a practical solution to this problem since at room temperature, PL lines undergo homogenous broadening. ${ }^{82}$ Single-photon emission at RT, with strong photon anti-bunching, has been collected from single $\mathrm{CsPbBr}_{3}$ and $\mathrm{CsPb}(\mathrm{Br} / \mathrm{I})_{3} \mathrm{NCs}^{82}$ The suppression of multi-photon events was attributed to fast non-radiative Auger recombination, which renders multiexciton states virtually non-emissive (the fraction of multi photon coincidence events was $\sim 6 \%$ on average). However, irreversible photo-degradation and blinking still occurred in these samples. On the contrary, other groups reported strongly reduced blinking, still with the retention of photon anti-bunching. ${ }^{83}$ As with conventional QDs, the reported variability in the degree of blinking and stability can be attributed to the structural integrity of NCs, their surface chemistry and environmental effects. For instance, as discussed earlier, $\mathrm{CsPbI}_{3}$ is known for its propensity to convert into a non-luminescent $1 \mathrm{D}$-polymorph. The speed of this phase-transition is governed by its exposure to moisture and oxygen (although not by oxidation), thus explaining vastly different reports on the behavior of $\mathrm{CsPb}_{3}$ at a singleparticle level. Furthermore, systematic studies of Auger recombination rates as a function of NC size and composition have only just begun. ${ }^{84}$

With the fast development of RT-operational, single-photon emitters from LHPs, practical applications in quantum technologies might soon be within a reach. In the development of new devices, colloidal LHP NCs offer unique and advantageous attributes: low-cost synthesis, excellent spectral versatility (wavelength range, emission linewidth) and facile, solution-based deposition onto virtually any substrate. A specific future device, among others, is a single-photon LED (Fig. 6f), wherein LHP NCs will be integrated into a shotnoise limited, lightweight single photon source operating at RT and covering the entire visible spectrum, a technology outlook that is difficult to foresee with other existing quantum materials. Two possible device architectures are foreseen: (i) electrical injection of the carriers into a single perovskite NC as already being demonstrated in other quantum systems (organic molecules or NV-centers in diamond) ${ }^{85,86}$ or (ii) integration of single NCs onto solid-state light sources (LEDs or lasers) as down-converting, single-photon sources. Ultrafast radiative recombination from individual LHP NCs will be beneficial, for instance, 
523 for quantum key distribution, wherein high transmission bit rate is paramount.

524 Furthermore, by combining NCs with different emission wavelengths on the same platform,

525 an interesting opportunity might arise from wavelength-multiplexing, which is adapting old 526 approaches from classical telecommunications to future, much-faster quantum 527 communication. Ultra-fast LHP single photon sources might also find applications in 528 advanced quantum metrology, from the calibration of photodetectors to the redefinition of 529 the candela.

\section{Open questions and beyond oD}

531

532

533

534

535

Given the rate at which scientific results related to LHP NCs are published, it is not surprising that the literature is sometimes controversial; only through careful and less precipitous investigations can these ongoing issues be settled. For instance, $\mathrm{CsPbBr} \mathrm{NCs}_{3}$ were initially assigned as a cubic phase, ${ }^{9}$ but deeper analysis revealed that this phase is actually orthorhombic and exhibits highly dynamic structural disorder. ${ }^{87}$ Even more debated issues are related to the correct assignment of optical and electronic structures to specific phases and compositions of cesium lead halides. Cesium, lead and bromine, for example, can crystallize into $\mathrm{CsPBBr}_{3}$ perovskite or into non-perovskite phases, $\mathrm{CsPb}_{2} \mathrm{Br}_{5}$ and $\mathrm{Cs}_{4} \mathrm{PbBr}_{6}$. The latter non-perovskite has been reported to be green-luminescent by several groups, but at the similar wavelengths at which the emission of $\mathrm{CsPBr}_{3}$ is usually observed (ca. $520 \mathrm{~nm}){ }^{88}$ Contrarily, other groups report larger bandgaps for both $\mathrm{Cs}_{4} \mathrm{PbBr}_{6}$ and $\mathrm{CsPb}_{2} \mathrm{Br}_{5}$, with no luminesce at all. ${ }^{46,89}$ The compositional and structural complexity of LHP NCs is only starting to be fully recognized and rationalized.

It is clear that LHPs have enticed materials scientists, chemists and physicists to further development the, yet fundamental, research of LHP NCs, as well as finding ways the implement their applications. In our opinion, efficient pure-color or white-light generation with LHPs will gain increasing scientific interest and, very likely, will turn into a great commercial opportunity in the near future (in displays, lighting and other applications). In this regard, we would like to emphasize that colloidal $\mathrm{APbX}_{3}$-type $\mathrm{NCs}$ are not the only promising forms of LHPs as versatile photonic sources. Quantum-confined LHPs can also be obtained in a stable bulk form. A notable case is that of the 2D Ruddlesden-Popper phases, in which $3 \mathrm{D}$-like layers of $\left[\mathrm{PbX}_{6}\right]$ octahedra are electronically disconnected by the partial replacement of Cs/MA/FA cations with larger cations such as butylammonium. These can be 
obtained as polycrystalline materials or as thin-films. ${ }^{90,91}$ Such "2D" perovskites share many similarities with the aforementioned colloidally synthesized LHP nanoplates/nanosheets, due to their strong quantum-confinement in one dimension. Combining the essential properties of colloidal LHP NCs and bulk 2D perovskites to achieve "multidimensional 3D/2D" LHP NCs has proved to be an interesting avenue of research, wherein the dimensionality of the electronic structure is engineered on both the atomic scale and nanoscale. ${ }^{92-94}$ This, and other research opportunities described in this review, will likely reveal their real potential soon.

\section{BOX 1: History of $\mathrm{CsPbX}_{3}$ and other LHP NCs}

Although metal halide NCs may appear to be newcomers in materials science, this is rather a misconception. The earliest reports of particulate semiconductor systems known to exhibit crystal size effects on the excitonic optical absorption and emission spectra were $\mathrm{CuCl}$ nanocrystallites in a $\mathrm{NaCl}$ matrix (in 1950s) ${ }^{95}$ and, a decade later, AgI colloids (1967). ${ }^{96}$ Decades later, glass- and $\mathrm{NaCl}$-embedded copper halide QDs played a historic role in the theoretical rationalization of quantum-size effects. ${ }^{97,}, 98$

The history of bulk cesium LHP materials extends much further back in time. The existence of crystalline compounds with composition $\mathrm{CsPbX}_{3}$, as well as $\mathrm{CsPb}_{2} \mathrm{X}_{5}$ and $\mathrm{Cs}_{4} \mathrm{PbX}_{6}$, was first reported in the $1890 s .{ }^{99}$ In $1957-1958, \mathrm{CsPD}_{3}$ were found to crystallize in a perovskite-type lattice and exhibit photoconductivity. ${ }^{100,}{ }^{101}$ High ionic conductivity, presently known as a reason for the electronic instability of perovskite materials as photovoltaics (PV) and a significant factor enabling fast ion-exchange in LHP NCs, was already reported for $\mathrm{CsPb}_{3}$ in the 1980 . $^{102}$

The line of research that would prove to be influential in the eventual discovery of colloidal $\mathrm{CsPbX}_{3} \mathrm{NCs}$ in 2015, began in the 1970s and concerned crystalline CsX materials doped with $\mathrm{Pb}^{2+}$ ions (typically at $0.01-1$ at $\%$ doping levels). The interest in these materials stemmed from their potential as fast X-ray scintillators for the detection of ionizing radiation due to bright PL with short (ns- to sub-ns, or even tens of ps in chlorides) radiative lifetimes and high photon yield under high energy excitation. The RT-emission peak at ca. $2.45 \mathrm{eV}$ (506 nm) of $\mathrm{Pb}$-doped $\mathrm{CsBr}$ single crystals was discovered, at latest, in the $1970 \mathrm{~s}^{103}$, and its origin was attributed, until the mid-199os, to the intra-atomic emission of $\mathrm{Pb}^{2+}$-related centers under the effect of Jahn-Teller splitting of the $\mathrm{ns}^{2}$ cations. The more recent interpretation of the bright 
PL in the visible spectrum of Pb-doped CsX melt-grown single crystals and thermally evaporated thin-film materials arose in the mid-199os. The existence of few-nm sized, fluorescent inclusions of $\mathrm{CsPbX}_{3}$ is now proposed to account for this bright PL, and the fact that the observed emission is often shifted to higher energies than that of bulk $\mathrm{CsPb}_{3}$ is attributed to quantum-size effects. For example, the $\mathrm{PL}$ of $\mathrm{Pb}^{2+}$ doped $\mathrm{CsCl}$ single crystals at 400-420 $\mathrm{nm}$ was interpreted to be due to excitonic emission from $\mathrm{CsPCl}_{3}$ clusters in 1995 , an then also in $\mathrm{Pb}$-doped $\mathrm{CsBr}^{104-106}$ It is not surprising that $\mathrm{CsPbX}_{3}$ nanoscale inclusions remained undetected for so long, owing to the combined effect of very low Pb-content, significant broadening of XRD reflections at sub-10 $\mathrm{nm}$ sizes and low electronic contrast between the $\mathrm{CsX}$ matrix and $\mathrm{CsPbX}_{3}$ inclusions (i.e., similar X-ray scattering factors). To induce the formation of nanosized $\mathrm{CsPbX}_{3}$ inclusions in the $\mathrm{CsX}$ matrix on purpose and reproducibly, Pb-doped CsX single crystals grown by Bridgman or Stockbarger methods or as polycrystalline materials must be annealed for $10-100$ hours at $150-300{ }^{\circ} \mathrm{C}$ to nucleate $\mathrm{CsPbX}_{3}$. These annealing temperatures are sufficiently high to induce the motion and aggregation of ions, yet still below the melting points of the CsX matrix. Interestingly, the different PL spectra observed for samples annealed at 210 and $240{ }^{\circ} \mathrm{C}$ suggest the possibility that nonspherical, platelet-like $\mathrm{CsPbCl}_{3} \mathrm{NC}_{\text {s were formed. }}{ }^{105}$ Multiple PL bands at shorter wavelengths (down to $390 \mathrm{~nm}$ ) were quantitatively modelled as lattice-matched, atomically flat quantum wells of various thicknesses, with the thinnest being around $2.4 \mathrm{~nm}$ (corresponding to ca. 4 unit cells).

From the late 1990 on on, considerable attention has also been devoted to thin $\mathrm{CsPbX}_{3}$ films with reduced CsX excess, typically thermally evaporated and up to several $\mu \mathrm{m}$ in thickness. ${ }^{107^{-}}$ ${ }^{109}$ Very bright PL with quantum-size effects on excitonic emission was reported for $\mathrm{CsPBr}_{3}$ films that had initially been deposited in an amorphous phase at $77 \mathrm{~K}$ and which were then heated to RT to induce crystallization into a nanocrystalline state. Such films even exhibited stimulated emission at room-temperature under ns-pulsed excitation $\left(0.5 \mathrm{~ns}\right.$, at $0.5 \mathrm{~kW} \mathrm{~cm}^{-2}$ average threshold). ${ }^{108}$

These early observations, as well as the widespread general attention for $\mathrm{MAPbX}_{3}$ compounds as absorber materials for highly efficient PV in recent years and the notion that all-inorganic compositions of LHPs are generally superior for chemical stability, motivated the development of the hot-injection synthesis routes to $\mathrm{CsPbX}_{3} \mathrm{NCs} .{ }^{9}$ These NCs were the 
first in the colloidal NC family to exhibit bright PL over the entire visible spectral range, without electronic surface passivation; they are characterized by high PLQYs (up to >90\%) and a narrow full width at half maximum (FWHM) of $<100 \mathrm{meV}(12-42 \mathrm{~nm})$.

In a similar way, the history of organic-inorganic hybrid LHPs can be traced back to later 1970s, when the synthesis and crystal structures of $\mathrm{MAPbX}_{3}$ were introduced. ${ }^{110}$ The structure and properties of $\mathrm{FAPbBr}_{3}$ and $\mathrm{FAPbI}_{3}$ have been reported only in the last decade. Works on particulate toluene dispersions of MA-based and other alkylammonium lead halides can be found since 2012-2013. ${ }^{111}, 12$ Much improved colloidal dispersibility of $\mathrm{MAPbBr}_{3}$ nanoparticles was obtained with ligand-assisted re-precipitation method in the presence of long-chain ligands, first introduced by in 2014. ${ }^{8}$ Colloidal platelet-like and cuboidal $\mathrm{FAPbBr}_{3}$ and $\mathrm{FAPbI}_{3}$ NCs were reported since $2015 \cdot 34,13-115$

\section{Acknowledgements}

Q.A.A and L.M. thank the 7th European Community Framework Programme under grant agreement no. 614897 (ERC Consolidator Grant "TRANS-NANO") for funding. M.V.K. is grateful for financial support by the European Research Council under the European Union's Seventh Framework Program (Grant Agreement Nr. 306733, ERC Starting Grant “NANOSOLID"). We thank Dr. Nicholas Stadie for reading the manuscript.

\section{References}

1. Huang, H. et al. Colloidal Lead Halide Perovskite Nanocrystals: Synthesis, Optical Properties and Applications. NPG Asia Mater. 8, e328 (2016).

2. Weidman, M. C., Goodman A. J. \& Tisdale W. A. Colloidal Halide Perovskite Nanoplatelets: An Exciting New Class of Semiconductor Nanomaterials. Chem. Mater. 29, 5019-5030 (2017).

3. Kovalenko, M. V., Protesescu L. \& Bodnarchuk M. I. Properties and Potential Optoelectronic Applications of Lead Halide Perovskite Nanocrystals. Science 358, 745-750 (2017).

4. Murray, C. B., Norris D. J. \& Bawendi M. G. Synthesis and Characterization of Nearly Monodisperse $\mathrm{CdE}$ (E = Sulfur, Selenium, Tellurium) Semiconductor Nanocrystallites. J. Am. Chem. Soc. 115, 87068715 (1993).

5. Saparov, B. \& Mitzi D. B. Organic-Inorganic Perovskites: Structural Versatility for Functional Materials Design. Chem. Rev. 116, 4558-4596 (2016).

6. Li, W. et al. Chemically Diverse and Multifunctional Hybrid Organic-Inorganic Perovskites. Nat. Rev. Mater. 2, 16099 (2017). 
7. Srivastava, V. et al. Understanding and Curing Structural Defects in Colloidal Gaas Nanocrystals. Nano Lett. 17, 2094-2101 (2017).

8. Schmidt, L. C. et al. Nontemplate Synthesis of $\mathrm{CH}_{3} \mathrm{NH}_{3} \mathrm{PbBr}_{3}$ Perovskite Nanoparticles. J. Am. Chem. Soc. 136, 850-853 (2014).

9. Protesescu, L. et al. Nanocrystals of Cesium Lead Halide Perovskites ( $\mathrm{CsPbX}_{3}, \mathrm{X}=\mathrm{Cl}, \mathrm{Br}$, and I): Novel Optoelectronic Materials Showing Bright Emission with Wide Color Gamut. Nano Lett. 15, 36923696 (2015).

10. Huang, H. et al. Growth Mechanism of Strongly Emitting $\mathrm{CH}_{3} \mathrm{NH}_{3} \mathrm{PbBr}_{3}$ Perovskite Nanocrystals with a Tunable Bandgap. Nat. Commun. 8, 996 (2017).

11. Sichert, J. A. et al. Quantum Size Effect in Organometal Halide Perovskite Nanoplatelets. Nano Lett. 15, 6521-6527 (2015).

12. Bekenstein, Y. et al. Highly Luminescent Colloidal Nanoplates of Perovskite Cesium Lead Halide and Their Oriented Assemblies. J. Am. Chem. Soc. 137, 16008-16011 (2015).

13. Akkerman, Q. A. et al. Solution Synthesis Approach to Colloidal Cesium Lead Halide Perovskite Nanoplatelets with Monolayer-Level Thickness Control. J. Am. Chem. Soc. 138, 1010-1016 (2016).

14. Tong, Y. et al. Highly Luminescent Cesium Lead Halide Perovskite Nanocrystals with Tunable Composition and Thickness by Ultrasonication. Angew. Chem. Int. Edit. 55, 13887-13892 (2016).

15. Zhu, Z.-Y. et al. Solvent-Free Mechanosynthesis of Composition-Tunable Cesium Lead Halide Perovskite Quantum Dots. J. Phys. Chem. Lett. 8, 1610-1614 (2017).

16. Pan, Q. et al. Microwave-Assisted Synthesis of High-Quality All-Inorganic $\mathrm{CsPbX}_{3}(\mathrm{X}=\mathrm{Cl}, \mathrm{Br}, \mathrm{I})$ Perovskite Nanocrystals and the Application in Light Emitting Diode. J. Mater. Chem. C 5, 1094710954 (2017).

17. Chen, S. et al. Exploring the Stability of Novel Wide Bandgap Perovskites by a Robot Based High Throughput Approach. Adv. Energy Mater.1701543 (2017).

18. Lignos, I. et al. Synthesis of Cesium Lead Halide Perovskite Nanocrystals in a Droplet-Based Microfluidic Platform: Fast Parametric Space Mapping. Nano Lett. 16, 1869-1877 (2016).

19. Dirin, D. N. et al. Harnessing Defect-Tolerance at the Nanoscale: Highly Luminescent Lead Halide Perovskite Nanocrystals in Mesoporous Silica Matrixes. Nano Lett. 16, 5866-5874 (2016).

20. Malgras, V. et al. Observation of Quantum Confinement in Monodisperse Methylammonium Lead Halide Perovskite Nanocrystals Embedded in Mesoporous Silica. J. Am. Chem. Soc. 138, 1387413881 (2016).

21. Huang, H. et al. Lead Halide Perovskite Nanocrystals in the Research Spotlight: Stability and DefectTolerance. ACS Energy Lett. 2, 2071-2083 (2017).

22. Brandt, R. E., Stevanović V., Ginley D. S. \& Buonassisi T. Identifying Defect-Tolerant Semiconductors with High Minority-Carrier Lifetimes: Beyond Hybrid Lead Halide Perovskites. MRS Commun. 5, 265275 (2015).

23. Kang, J. \& Wang L.-W. High Defect Tolerance in Lead Halide Perovskite $\mathrm{CsPbBr}_{3}$. J. Phys. Chem. Lett. 8, 489-493 (2017).

24. Koscher, B. A., Swabeck J. K., Bronstein N. D. \& Alivisatos A. P. Essentially Trap-Free CsPbBr Colloidal Nanocrystals by Postsynthetic Thiocyanate Surface Treatment. J. Am. Chem. Soc. 139, 6566-6569 (2017).

25. Liu, F. et al. Highly Luminescent Phase-Stable $\mathrm{CsPbl}_{3}$ Perovskite Quantum Dots Achieving near 100\% Absolute Photoluminescence Quantum Yield. ACS Nano 11, 10373-10383 (2017).

26. Zhu, H. et al. Screening in Crystalline Liquids Protects Energetic Carriers in Hybrid Perovskites. Science 353, 1409-1413 (2016).

27. Bakulin, A. A. et al. Real-Time Observation of Organic Cation Reorientation in Methylammonium Lead lodide Perovskites. J. Phys. Chem. Lett. 6, 3663-3669 (2015).

28. Walsh, A. \& Zunger A. Instilling Defect Tolerance in New Compounds. Nat. Mater. 16, 964-967 (2017).

29. Boles, M. A., Ling D., Hyeon T. \& Talapin D. V. The Surface Science of Nanocrystals. Nat. Mater. 15, 141-153 (2016). 
30. De Roo, J. et al. Highly Dynamic Ligand Binding and Light Absorption Coefficient of Cesium Lead Bromide Perovskite Nanocrystals. ACS Nano 10, 2071-2081 (2016).

31. Trots, D. M. \& Myagkota S. V. High-Temperature Structural Evolution of Caesium and Rubidium Triiodoplumbates. J. Phys. Chem. Solids 69, 2520-2526 (2008).

32. Stoumpos, C. C., Malliakas C. D. \& Kanatzidis M. G. Semiconducting Tin and Lead lodide Perovskites with Organic Cations: Phase Transitions, High Mobilities, and near-Infrared Photoluminescent Properties. Inorg. Chem. 52, 9019-9038 (2013).

33. Swarnkar, A. et al. Quantum Dot-Induced Phase Stabilization of $\alpha-\mathrm{CsPbl}_{3}$ Perovskite for HighEfficiency Photovoltaics. Science 354, 92-95 (2016).

34. Protesescu, L. et al. Dismantling the "Red Wall" of Colloidal Perovskites: Highly Luminescent Formamidinium and Formamidinium-Cesium Lead lodide Nanocrystals. ACS Nano 11, 3119-3134 (2017).

35. Wang, C., Chesman A. S. R. \& Jasieniak J. J. Stabilizing the Cubic Perovskite Phase of $\mathrm{CsPbl}_{3}$ Nanocrystals by Using an Alkyl Phosphinic Acid. Chem. Commun. 53, 232-235 (2017).

36. Beal, R. E. et al. Cesium Lead Halide Perovskites with Improved Stability for Tandem Solar Cells. J. Phys. Chem. Lett. 7, 746-751 (2016).

37. Akkerman, Q. A. et al. Fluorescent Alloy $\mathrm{CsPb}_{x} \mathrm{Mn}_{1-x} \mathrm{l}_{3}$ Perovskite Nanocrystals with High Structural and Optical Stability. ACS Energy Lett. 2, 2183-2186 (2017).

38. Zou, S. et al. Stabilizing Cesium Lead Halide Perovskite Lattice through Mn(II) Substitution for AirStable Light-Emitting Diodes. J. Am. Chem. Soc. 139, 11443-11450 (2017).

39. Hu, Y. et al. Bismuth Incorporation Stabilized $\alpha-\mathrm{CsPb}_{3}$ for Fully Inorganic Perovskite Solar Cells. ACS Energy Lett. 2, 2219-2227 (2017).

40. Ai, B. et al. Precipitation and Optical Properties of $\mathrm{CsPbBr}_{3}$ Quantum Dots in Phosphate Glasses. J. Am. Ceram. Soc. 99, 2875-2877 (2016).

41. Liu, S. et al. Novel CsPbl ${ }_{3}$ QDs Glass with Chemical Stability and Optical Properties. J. Eur. Ceram. Soc. In Press, (2017).

42. Ai, B. et al. Low Temperature Photoluminescence Properties of $\mathrm{CsPbBr}_{3}$ Quantum Dots Embedded in Glasses. Phys. Chem. Chem. Phys. 19, 17349-17355 (2017).

43. $\mathrm{Di}$, X. et al. Use of Long-Term Stable $\mathrm{CsPbBr}_{3}$ Perovskite Quantum Dots in Phospho-Silicate Glass for Highly Efficient White Leds. Chem. Commun. 53, 11068-11071 (2017).

44. Nedelcu, G. et al. Fast Anion-Exchange in Highly Luminescent Nanocrystals of Cesium Lead Halide Perovskites ( $\mathrm{CsPbX}_{3}, \mathrm{X}=\mathrm{Cl}, \mathrm{Br}$, I). Nano Lett. 15, 5635-5640 (2015).

45. Akkerman, Q. A. et al. Tuning the Optical Properties of Cesium Lead Halide Perovskite Nanocrystals by Anion Exchange Reactions. J. Am. Chem. Soc. 137, 10276-10281 (2015).

46. Akkerman, $\mathrm{Q}$. A. et al. Nearly Monodisperse Insulator $\mathrm{Cs}_{4} \mathrm{PbX}_{6}(\mathrm{X}=\mathrm{Cl}, \mathrm{Br}$, I) Nanocrystals, Their Mixed Halide Compositions, and Their Transformation into CsPbX 3 Nanocrystals. Nano Lett. 17, 1924-1930 (2017).

47. van der Stam, W. et al. Highly Emissive Divalent-Ion-Doped Colloidal CsPb ${ }_{1-x} \mathrm{MxBr}_{3}$ Perovskite Nanocrystals through Cation Exchange. J. Am. Chem. Soc. 139, 4087-4097 (2017).

48. Barker, A. J. et al. Defect-Assisted Photoinduced Halide Segregation in Mixed-Halide Perovskite Thin Films. ACS Energy Lett. 2, 1416-1424 (2017).

49. De Trizio, L. \& Manna L. Forging Colloidal Nanostructures Via Cation Exchange Reactions. Chem. Rev. 116, 10852-10887 (2016).

50. Liu, W. et al. $\mathrm{Mn}^{2+}$-Doped Lead Halide Perovskite Nanocrystals with Dual-Color Emission Controlled by Halide Content. J. Am. Chem. Soc. 138, 14954-14961 (2016).

51. Guria, A. K., Dutta S. K., Adhikari S. D. \& Pradhan N. Doping $\mathrm{Mn}^{2+}$ in Lead Halide Perovskite Nanocrystals: Successes and Challenges. ACS Energy Lett. 2, 1014-1021 (2017).

52. Palazon, F. et al. Changing the Dimensionality of Cesium Lead Bromide Nanocrystals by Reversible Postsynthesis Transformations with Amines. Chem. Mater. 29, 4167-4171 (2017).

53. $\mathrm{Wu}$, L. et al. From Nonluminescent $\mathrm{Cs}_{4} \mathrm{PbX}_{6}(\mathrm{X}=\mathrm{Cl}, \mathrm{Br}, \mathrm{I})$ Nanocrystals to Highly Luminescent $\mathrm{CsPbX}$ Nanocrystals: Water-Triggered Transformation through a CsX-Stripping Mechanism. Nano Lett. 17, 5799-5804 (2017). 
54. Liu, Z. et al. Ligand Mediated Transformation of Cesium Lead Bromide Perovskite Nanocrystals to Lead Depleted $\mathrm{Cs}_{4} \mathrm{PbBr}_{6}$ Nanocrystals. J. Am. Chem. Soc. 139, 5309-5312 (2017).

55. Eperon, G. E. et al. Perovskite-Perovskite Tandem Photovoltaics with Optimized Band Gaps. Science 354, 861-865 (2016).

56. Saliba, M. et al. Incorporation of Rubidium Cations into Perovskite Solar Cells Improves Photovoltaic Performance. Science 354, 206-209 (2016).

57. Kovalenko, M. V. et al. Prospects of Nanoscience with Nanocrystals. ACS Nano 9, 1012-1057 (2015).

58. Zhang, H. et al. Embedding Perovskite Nanocrystals into a Polymer Matrix for Tunable Luminescence Probes in Cell Imaging. Adv. Funct. Mater. 27, 1604382 (2017).

59. Quan, L. N. et al. Highly Emissive Green Perovskite Nanocrystals in a Solid State Crystalline Matrix. Adv. Mater. 27, 1605945 (2017).

60. Guhrenz, C. et al. Solid-State Anion Exchange Reactions for Color Tuning of $\mathrm{CsPbX}_{3}$ Perovskite Nanocrystals. Chem. Mater. 28, 9033-9040 (2016).

61. Li, J. et al. 50-Fold EQE Improvement up to $6.27 \%$ of Solution-Processed All-Inorganic Perovskite CsPbBr ${ }_{3}$ QLEDs Via Surface Ligand Density Control. Adv. Mater. 29, 1603885 (2017).

62. Chiba, T. et al. High-Efficiency Perovskite Quantum-Dot Light-Emitting Devices by Effective Washing Process and Interfacial Energy Level Alignment. ACS Appl. Mater. Interfaces. 9, 18054-18060 (2017).

63. Zhang, X. et al. Bright Perovskite Nanocrystal Films for Efficient Light-Emitting Devices. J Phys Chem Lett 7, 4602-4610 (2016).

64. Deng, W. et al. Organometal Halide Perovskite Quantum Dot Light-Emitting Diodes. Adv. Funct. Mater. 26, 4797-4802 (2016).

65. Akkerman, Q. A. et al. Strongly Emissive Perovskite Nanocrystal Inks for High-Voltage Solar Cells. Nat. Energy 2, 16194 (2016).

66.

Http://Rohs.Exemptions.Oeko.Info/Fileadmin/User Upload/Rohs Pack 10/Cd Qd Exs Q d Vision D Qdv Supplemental Life-Cycle Analysis.Pdf.

67. Babayigit, A., Ethirajan A., Muller M. \& Conings B. Toxicity of Organometal Halide Perovskite Solar Cells. Nat. Mater. 15, 247-251 (2016).

68. Zhou, C. et al. Low-Dimensional Organic Tin Bromide Perovskites and Their Photoinduced Structural Transformation. Angew. Chem. Int. Edit. 56, 9018-9022 (2017).

69. Giustino, F. \& Snaith H. J. Toward Lead-Free Perovskite Solar Cells. ACS Energy Lett. 1, 1233-1240 (2016).

70. McCall, K. M. et al. Strong Electron-Phonon Coupling and Self-Trapped Excitons in the Defect Halide Perovskites $\mathrm{A}_{3} \mathrm{M}_{2} \mathrm{I}_{9}(\mathrm{a}=\mathrm{Cs}, \mathrm{Rb} ; \mathrm{M}=\mathrm{Bi}, \mathrm{Sb})$. Chem. Mater. (2017).

71. Slavney, A. H., Hu T., Lindenberg A. M. \& Karunadasa H. I. A Bismuth-Halide Double Perovskite with Long Carrier Recombination Lifetime for Photovoltaic Applications. J. Am. Chem. Soc. 138, 21382141 (2016).

72. Volonakis, G. et al. Lead-Free Halide Double Perovskites Via Heterovalent Substitution of Noble Metals. J. Phys. Chem. Lett. 7, 1254-1259 (2016).

73. Raino, G. et al. Single Cesium Lead Halide Perovskite Nanocrystals at Low Temperature: Fast SinglePhoton Emission, Reduced Blinking, and Exciton Fine Structure. ACS Nano 10, 2485-2490 (2016).

74. Becker, M. A. et al. Bright Triplet Excitons in Lead Halide Perovskites. Nature 2018, in print, first version: arXiv:1707.03071 (2017).

75. Efros, A. L. \& Nesbitt D. J. Origin and Control of Blinking in Quantum Dots. Nat. Nanotechnol. 11, 661-671 (2016).

76. Aharonovich, I., Englund D. \& Toth M. Solid-State Single-Photon Emitters. Nat. Photonics 10, 631641 (2016).

77. Fu, M. et al. Neutral and Charged Exciton Fine Structure in Single Lead Halide Perovskite Nanocrystals Revealed by Magneto-Optical Spectroscopy. Nano Lett. 17, 2895-2901 (2017).

78. Isarov, M. et al. Rashba Effect in a Single Colloidal $\mathrm{CsPbBr}_{3}$ Perovskite Nanocrystal Detected by Magneto-Optical Measurements. Nano Lett. 17, 5020-5026 (2017). 
79. Yin, C. et al. Bright-Exciton Fine-Structure Splittings in Single Perovskite Nanocrystals. Phys. Rev. Lett. 119, 026401 (2017).

80. Nirmal, M. et al. Observation of the "Dark Exciton" in CdSe Quantum Dots. Phys. Rev. Lett. 75, 3728-3731 (1995).

81. Tighineanu, P. et al. Single-Photon Superradiance from a Quantum Dot. Phys. Rev. Lett. 116, 163604 (2016).

82. Park, Y.-S., Guo S., Makarov N. S. \& Klimov V. I. Room Temperature Single-Photon Emission from Individual Perovskite Quantum Dots. ACS Nano 9, 10386-10393 (2015).

83. Hu, F. et al. Slow Auger Recombination of Charged Excitons in Nonblinking Perovskite Nanocrystals without Spectral Diffusion. Nano Lett. 16, 6425-6430 (2016).

84. Utzat, H. et al. Probing Linewidths and Biexciton Quantum Yields of Single Cesium Lead Halide Nanocrystals in Solution. Nano Lett. 17, 6838-6846 (2017).

85. Mizuochi, N. et al. Electrically Driven Single-Photon Source at Room Temperature in Diamond. Nat. Photonics 6, 299-303 (2012).

86. Nothaft, M. et al. Electrically Driven Photon Antibunching from a Single Molecule at Room Temperature. Nat. Commun. 3, 628 (2012).

87. Bertolotti, F. et al. Coherent Nanotwins and Dynamic Disorder in Cesium Lead Halide Perovskite Nanocrystals. ACS Nano 11, 3819-3831 (2017).

88. Saidaminov, M. I. et al. Pure $\mathrm{Cs}_{4} \mathrm{PbBr}_{6}$ : Highly Luminescent Zero-Dimensional Perovskite Solids. ACS Energy Lett. 1, 840-845 (2016).

89. Nikl, M. et al. Photoluminescence of $\mathrm{Cs}_{4} \mathrm{PbBr}_{6}$ Crystals and Thin Films. Chem. Phys. Lett. 306, 280284 (1999).

90. Mitzi, D. B. Synthesis, Crystal Structure, and Optical and Thermal Properties of (C4H9NH3)2MI4 (M $=\mathrm{Ge}, \mathrm{Sn}, \mathrm{Pb})$. Chem Mater 8, 791-800 (1996).

91. Blancon, J.-C. et al. Extremely Efficient Internal Exciton Dissociation through Edge States in Layered 2D Perovskites. Science 355, 1288-1292 (2017).

92. Bhaumik, S. et al. Highly Stable, Luminescent Core-Shell Type Methylammonium-Octylammonium Lead Bromide Layered Perovskite Nanoparticles. Chem. Commun. 52, 7118-7121 (2016).

93. Chen, W. et al. Giant Five-Photon Absorption from Multidimensional Core-Shell Halide Perovskite Colloidal Nanocrystals. Nat. Commun. 8, 15198 (2017).

94. Liu, F. et al. Highly Luminescent Phase-Stable $\mathrm{CsPbl}_{3}$ Perovskite Quantum Dots Achieving near $100 \%$ Absolute Photoluminescence Quantum Yield. ACS Nano 11, 10373-10383 (2017).

95. Gross, E. F. \& Kapliansky A. A. A Spectroscopic Study of Absorption and Luminescence of Cuprous Chloride, Introduced into a Crystal of Rock Salt. Opt. Spektrosk. 2, 204-209 (1957).

96. Berry, C. R. Structture and Opticcal Absorption of AgI Microcrystals. Phys. Rev. B 161, 848-851 (1967).

97. Ekimov, A. I. \& Onushchenko A. A. Quantum Size Effects in 3-Dimensional Microscopic Semiconductor Crystals. Jetp Lett. 34, 345-349 (1981).

98. Efros, A. L. Interband Absorption of Light in a Semiconductor Sphere. Sov. Phys. Semicond. 16, 772775 (1982).

99. Wells, H. L. Über Die Cäsium- Und Kalium-Bleihalogenide. Z. Anorg. Allg. Chem. 3, 195-210 (1893).

100. Moller, C. K. A Phase Transition in Caesium Plumbochloride. Nature 180, $981-982$ (1957).

101. Moller, C. K. Crystal Structure and Photoconductivity of Caesium Plumbohalides. Nature 182, 14361436 (1958).

102. Mizusaki, J., Arai K. \& Fueki K. Ionic-Conduction of the Perovskite-Type Halides. Solid State Ion. 11, 203-211 (1983).

103. Radhakrishna, S. Polarised Luminescence from Lead Centers in Cesium Halides. J. Lumin. 12, 409411 (1976).

104. Nikl, M. et al. Optical-Properties of the $\mathrm{Pb}^{2+}$ Based Aggregated Phase in a CsCl Host CrystalQuantum-Confinement Effects Phys. Rev. B 51, 5192-5199 (1995).

105. Nikl, M. et al. Quantum Size Effect in the Excitonic Luminescence of $\mathrm{CsPbX}_{3}$-Like Quantum Dots in CsX (X = Cl, Br) Single Crystal Host. J. Lumin. 72, 377-379 (1997). 
106. Aceves, R. et al. Spectroscopy of $\mathrm{CsPbBr}_{3}$ Quantum Dots in CsBr:Pb Crystals. J. Lumin. 93, 27-41 (2001).

107. Kondo, S., Sakai T., Tanaka H. \& Saito T. Amorphization-Induced Strong Localization of Electronic States in $\mathrm{CsPbBr}_{3}$ and $\mathrm{CsPbCl}_{3}$ Studied by Optical Absorption Measurements. Phys. Rev. B 58, 1140111407 (1998).

108. Kondo, S. et al. High Intensity Photoluminescence of Microcrystalline $\mathrm{CsPbBr}_{3}$ Films: Evidence for Enhanced Stimulated Emission at Room Temperature. Curr. Appl. Phys. 7, 1-5 (2007).

109. Kondo, S., Saito T., Asada H. \& Nakagawa H. Stimulated Emission from Microcrystalline CsPbBr Films: Edge Emission Versus Surface Emission. Mater. Sci. Eng. B 137, 156-161 (2007).

110. Weber, D. $\mathrm{CH}_{3} \mathrm{NH}_{3} \mathrm{PbX}$, Ein $\mathrm{Pb}$ (II)-System Mit Kubischer Perowskitstruktur/ $\mathrm{CH}_{3} \mathrm{NH}_{3} \mathrm{PbX}$, a $\mathrm{Pb}$ (II)System with Cubic Perovskite Structure. Z. Naturforsch. B 33, 1443-1445 (1978).

111. Papavassiliou, G. C. et al. Nanocrystalline/Microcrystalline Materials Based on Lead-Halide Units. J. Mater. Chem. 22, 8271-8280 (2012).

112. Papavassiliou, G. C., Pagona G., Mousdis G. A. \& Karousis N. Enhanced Phosphorescence from Nanocrystalline/Microcrystalline Materials Based on $\left(\mathrm{CH}_{3} \mathrm{NH}_{3}\right)(1-\mathrm{Naphthylmethyl}$ Ammonium $)_{2} \mathrm{~Pb}_{2} \mathrm{Cl}_{7}$ and Similar Compounds. Chem. Phys. Lett. 570, 80-84 (2013).

113. Aygüler, M. F. et al. Light-Emitting Electrochemical Cells Based on Hybrid Lead Halide Perovskite Nanoparticles. J. Phys. Chem. C 119, 12047-12054 (2015).

114. Weidman, M. C., Seitz M., Stranks S. D. \& Tisdale W. A. Highly Tunable Colloidal Perovskite Nanoplatelets through Variable Cation, Metal, and Halide Composition. ACS Nano 10, 7830-7839 (2016).

115. Protesescu, L. et al. Monodisperse Formamidinium Lead Bromide Nanocrystals with Bright and Stable Green Photoluminescence. J. Am. Chem. Soc. 138, 14202-14205 (2016). 


\section{c Structure dynamics}

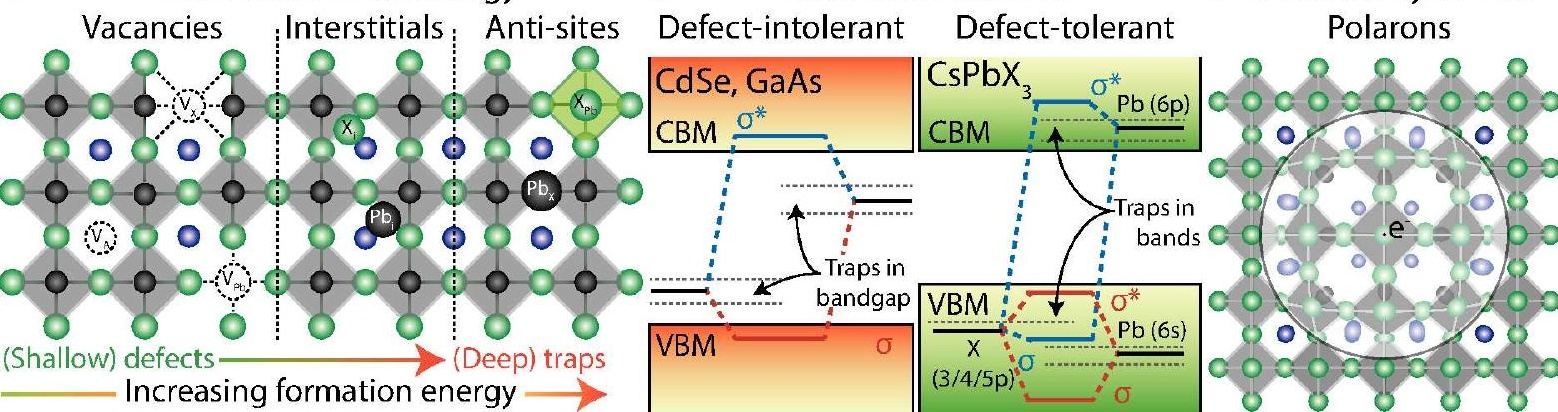


a

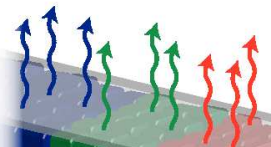

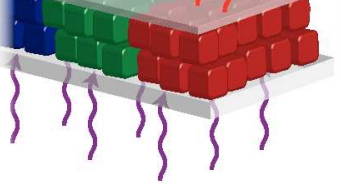

Down conversion

b

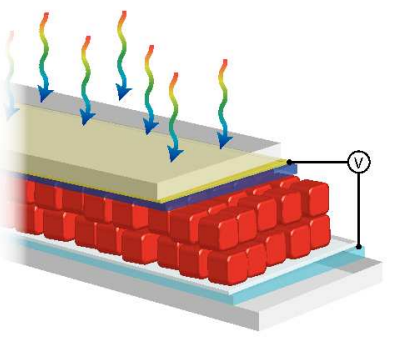

Light absorption

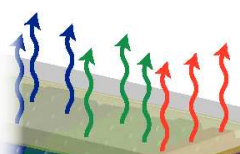

LEDs

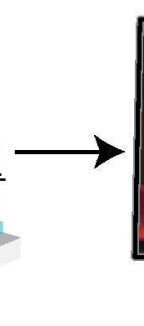

TVs and lighting applications

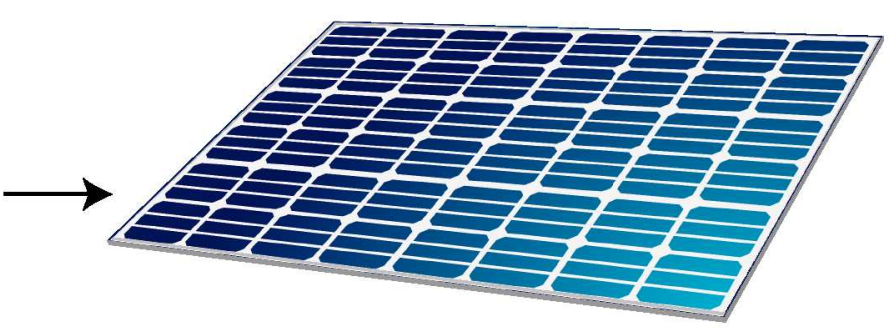

Solar cells 
a

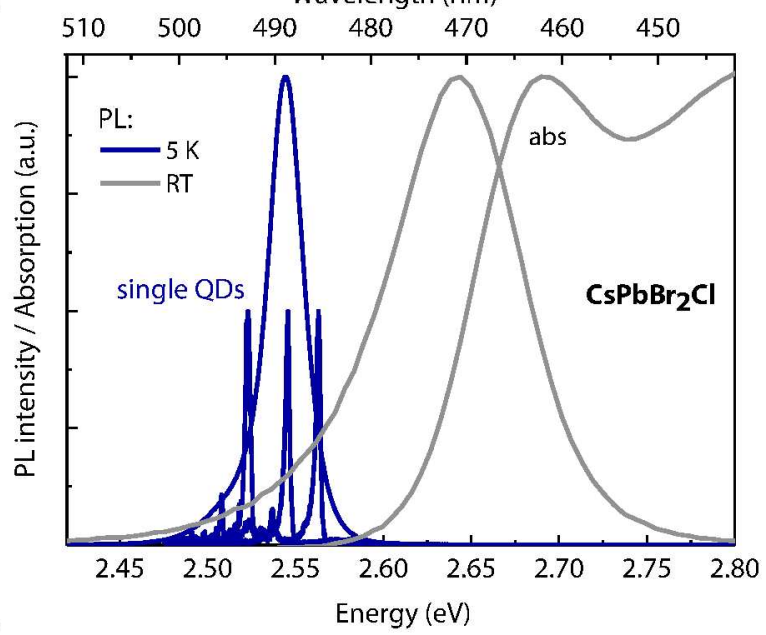

C
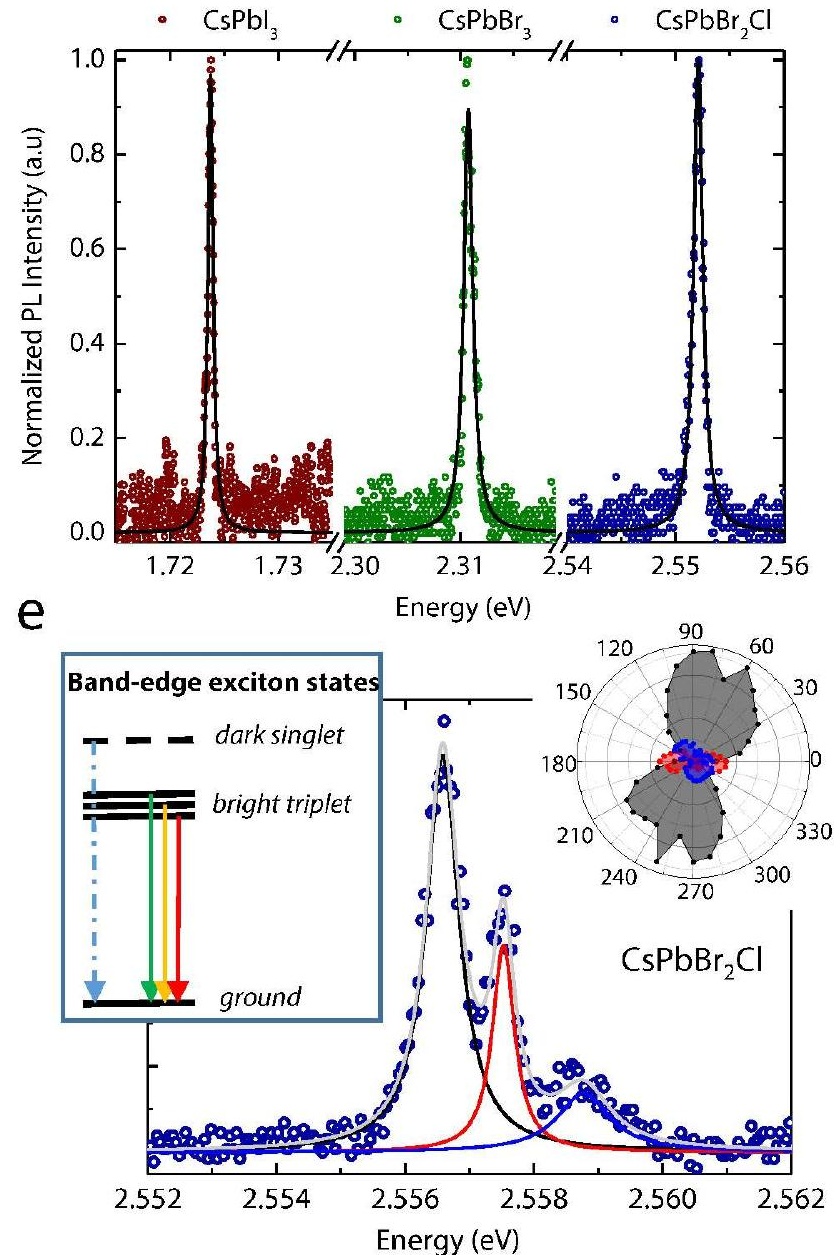

b
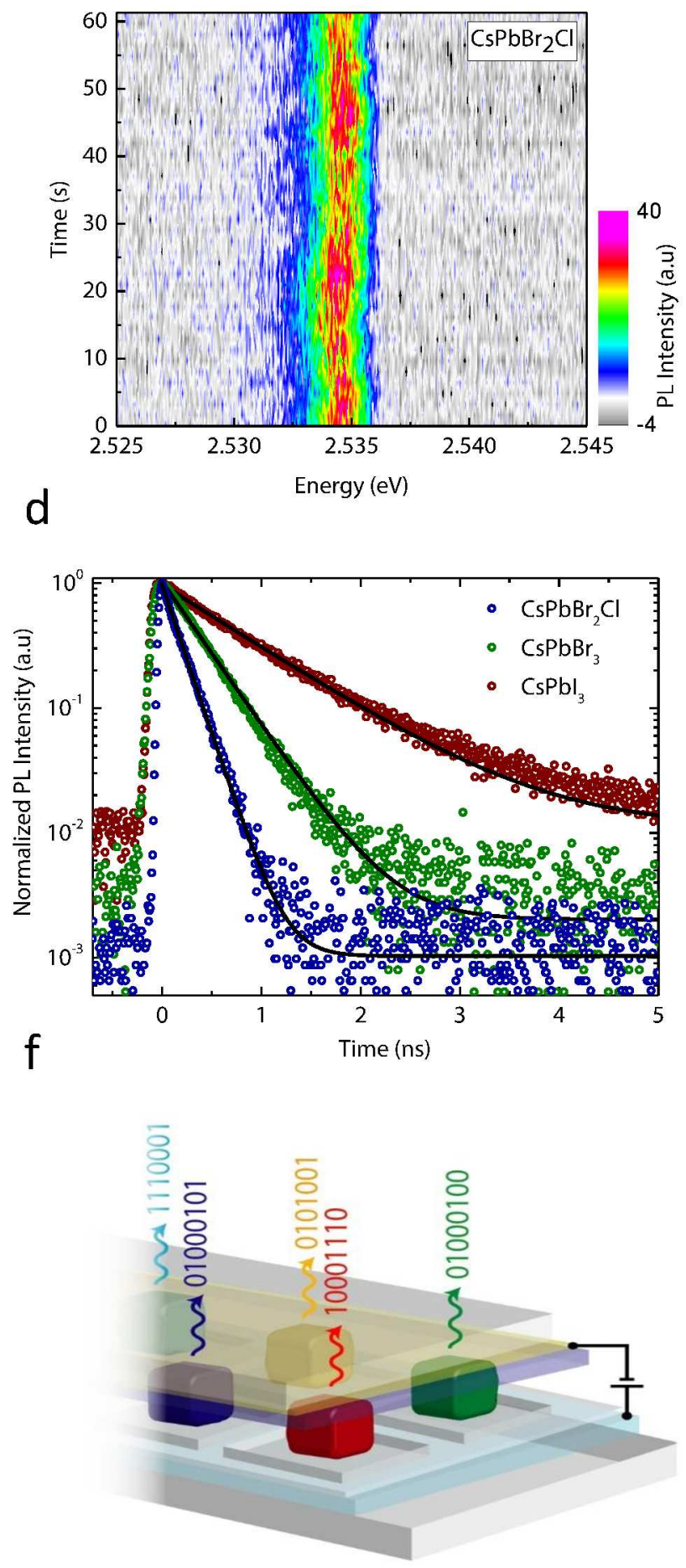
Table 1. Comparison of the chemistry, durability and optical performance of LHP NCs with conventional NCs. Only NCs emissive in the visible spectral range are included.

\begin{tabular}{|c|c|c|c|}
\hline & $\begin{array}{l}\text { Metal chalcogenide (II-VI) } \\
\text { and pnictide (InP) core- } \\
\text { only nanocrystals }\end{array}$ & $\begin{array}{l}\text { Metal chalcogenide and } \\
\text { pnictide core/shell } \\
\text { nanocrystals }\end{array}$ & $\begin{array}{l}\text { Lead halide perovskite } \\
\text { nanocrystals }\end{array}$ \\
\hline Crystal structure & wurtzite, zinc-blende & wurtzite, zinc-blende & perovskite \\
\hline Composition & CdSe, ZnSe, InP & $\mathrm{CdSe} / \mathrm{CdS}, \mathrm{CdSe} / \mathrm{CdZnS}, \mathrm{InP} / \mathrm{ZnS}$ & $\begin{array}{ll}\mathrm{Cs}, \mathrm{FA}) \mathrm{PbX}_{3} \quad(\mathrm{X}=\mathrm{Cl}, & \mathrm{Br}, \quad \mathrm{I}), \\
\text { homogeneous, } & \text { multinary } \\
\text { compositions possible } & \\
\end{array}$ \\
\hline Used in & no commercial use & $\begin{array}{l}\text { LCD TV (Samsung, Sony, etc.), } \\
\text { discontinued for Cd-based. }\end{array}$ & under development for LCD TV \\
\hline $\begin{array}{l}\text { Spectral range and } \\
\text { efficiency }\end{array}$ & $\begin{array}{l}\text { entire visible }(400-700 \mathrm{~nm}) \text { for II- } \\
\text { VI and limited for InP (520-700 } \\
\mathrm{nm})\end{array}$ & limited $(510-650 \mathrm{~nm})$ & entire visible (400-70o $\mathrm{nm})$ \\
\hline PL QY & low $(0-10 \%)$ & high (up to $95 \%$ ) & high (up to $99+\%$ ) \\
\hline FWHM & \multicolumn{2}{|c|}{$\begin{array}{l}\text { narrow for II-VI (<25 nm; e.g. <100 meV), but limited for InP-based (ca. } \\
40 \mathrm{~nm} \text { at } 530 \mathrm{~nm} \text { PL peak) }\end{array}$} & $\begin{array}{l}\text { narrow over entire visible range } \\
(<100 \mathrm{meV})\end{array}$ \\
\hline Defectiveness & $\begin{array}{l}\text { low in binary compounds; high in } \\
\text { antisites and interstitials) }\end{array}$ & multinary compositions (vacancies, & intrinsically high (vacancies) \\
\hline Synthesis & $\begin{array}{l}\text { high-purity precursors and } \\
\text { rigorous air-free synthesis; high- } \\
\text { temperature }\end{array}$ & $\begin{array}{l}\text { elaborate, lengthy synthesis; high- } \\
\text { temperatures }\end{array}$ & $\begin{array}{l}\text { facile synthesis; possible under } \\
\text { ambient conditions }\end{array}$ \\
\hline $\begin{array}{l}\text { Post-synthesis } \\
\text { tunability }\end{array}$ & \multicolumn{2}{|l|}{ only cation exchange } & $\begin{array}{l}\text { cation exchange (both } \mathrm{A} \text { and } \mathrm{B} \\
\text { sites) and anion exchange }\end{array}$ \\
\hline Surface ligands & \multicolumn{2}{|c|}{ highly versatile organic and inorganic surface functionalization } & $\begin{array}{l}\text { limited affinity to the surfaces; } \\
\text { new ligand chemistries are } \\
\text { urgently needed }\end{array}$ \\
\hline $\begin{array}{l}\text { Heteronanostructu } \\
\text { res }\end{array}$ & \multicolumn{2}{|c|}{ yes (complex core shells/dumbbells/Janus etc.) } & none to date \\
\hline Thermal stability & stable & stable & limited to below $100{ }^{\circ} \mathrm{C}$ due to low \\
\hline
\end{tabular}




\begin{tabular}{|c|c|c|c|}
\hline & & & melting points \\
\hline $\begin{array}{l}\text { Oxidative and } \\
\text { photostability }\end{array}$ & low to moderate & high & high \\
\hline $\begin{array}{l}\text { Solvent } \\
\text { compatibility }\end{array}$ & \multicolumn{2}{|c|}{ compatible with all solvents, including water } & $\begin{array}{l}\text { finite solubility in water and many } \\
\text { polar solvents, insoluble in all } \\
\text { others }\end{array}$ \\
\hline RoHS compliance & \multicolumn{2}{|c|}{ limited for CdSe-based (100 ppm limit for Cd), unlimited for InP-based } & $\begin{array}{l}\text { limited but higher than for CdSe- } \\
\text { based (10oo ppm limit for } \mathrm{Pb} \text { ) }\end{array}$ \\
\hline \multicolumn{4}{|c|}{ Single-dot PL } \\
\hline $\begin{array}{l}\text { Single-photon } \\
\text { emission }\end{array}$ & yes & yes & yes \\
\hline $\begin{array}{l}\text { Multi-exciton } \\
\text { emisison }\end{array}$ & low yield & high yield & high yield \\
\hline Blinking & yes & reduced & reduced \\
\hline Photobleaching & fast & moderate & moderate \\
\hline Emission rate & $\begin{array}{l}\sim 10 \mathrm{~ns}(\mathrm{RT}) \\
\text { sub- } \mu \mathrm{s}\left({ }_{5} \mathrm{~K}\right)\end{array}$ & $\begin{array}{l}\text { 10-100 ns (RT), } \\
\text { sub- } \mu \mathrm{s}(5 \mathrm{~K})\end{array}$ & $\begin{array}{l}\text { 1-5o ns, longer for iodides (RT), } \\
\text { sub-ns }(5 \mathrm{~K})\end{array}$ \\
\hline
\end{tabular}

